\title{
A human rights-consistent approach to multidimensional welfare measurement applied to sub-Saharan Africa
}

Arndt, Channing; Mahrt, Kristi; Hussain, M. Azhar; Tarp, Finn

Published in:

World Development

DOI:

10.1016/j.worlddev.2018.03.022

Publication date:

2018

Document version

Publisher's PDF, also known as Version of record

Document license:

CC BY-NC-ND

Citation for published version (APA):

Arndt, C., Mahrt, K., Hussain, M. A., \& Tarp, F. (2018). A human rights-consistent approach to multidimensional welfare measurement applied to sub-Saharan Africa. World Development, 108, 181-196.

https://doi.org/10.1016/j.worlddev.2018.03.022 


\title{
A human rights-consistent approach to multidimensional welfare measurement applied to sub-Saharan Africa
}

\author{
Channing Arndt ${ }^{\mathrm{a}, *}$, Kristi Mahrt ${ }^{\mathrm{a}}$, M. Azhar Hussain ${ }^{\mathrm{b}}$, Finn Tarp ${ }^{\mathrm{c}}$ \\ ${ }^{a}$ Environment and Production Technology Division (EPT), International Food Policy Research Institute (IFPRI), 1201 Eye St, NW, Washington, DC 20005, USA \\ ${ }^{b}$ Department of Finance \& Economics, University of Sharjah, UAE and Department of Social Sciences E Business, Roskilde University, Denmark \\ ${ }^{\mathrm{c}}$ United Nations University World Institute for Development Economics Research (UNU-WIDER), Katajanokanlaituri 6 B, FI-00160 Helsinki, Finland
}

\section{A R T I C L E I N F O}

\section{Article history:}

Accepted 17 March 2018

Available online 13 April 2018

\section{JEL classification:}

C81

D39

D63

I3

012

055

\section{Keywords:}

First-order dominance

Multidimensional welfare measurement

Sub-Saharan Africa

Demographic and Health Survey

Human rights-based approach

\begin{abstract}
A B S T R A C T
The rights-based approach to development targets progress towards the realization of 30 articles set forth in the Universal Declaration of Human Rights. In current practice, progress is frequently measured using the multidimensional poverty index. While elegant and useful, the multidimensional poverty index is inconsistent with the Universal Declaration of Human Rights principles of indivisibility, inalienability, and equality. We argue that a first-order dominance (FOD) methodology maintains basic consistency with these principles. Specifically, FOD comparisons are independent of any applied weighting schemes and hence are free from assumptions regarding substitutability between included welfare indicators (indivisibility). FOD cannot be established when welfare in any indicator is deteriorating, no matter how great the advancement is in other indicators (inalienability). Finally, FOD requires that domination occurs throughout the population (equality), implying that welfare gains among better-off groups never offset welfare losses among worse-off groups. We discuss and compare the properties of the multidimensional poverty index and first-order dominance approach and apply both measures to 26 African countries using data near 2002 and 2012. Results across the two measures are broadly similar but not the same. For example, while the multidimensional poverty index suggests that all countries are advancing, FOD indicates that 14 countries experience broad-based progress, two countries show more moderate likelihoods of progress, and the remaining 10 countries neither improve nor deteriorate in terms of attainment of rights for the dimensions considered. We conclude that the multidimensional poverty index and first-order dominance approaches are useful complements that should be employed in tandem.

(c) 2018 UNU-WIDER. Published by Elsevier Ltd. This is an open access article under the CC BY-NC-ND license (http://creativecommons.org/licenses/by-nc-nd/4.0/).
\end{abstract}

\section{Introduction}

On December 10, 1948, the United Nations General Assembly (UNGA) adopted the Universal Declaration of Human Rights (UDHR) as 'a common standard of achievement for all peoples and all nations'. The UDHR contains 30 articles that define a series of fundamental human rights. Most of these articles refer to laws or norms that govern the functioning of society. For example, Article 2 states that the rights and freedoms set forth in the UDHR apply without distinction of any kind, such as race, religion, or sex; and Article 15 affirms that everyone has a right to a nationality. These and most other articles within the Declaration can in principle be followed without reference to the material circumstances

\footnotetext{
* Corresponding author.

E-mail addresses: C.Arndt@cgiar.org (C. Arndt), mazhar@sharjah.ac.ae (M.A. Hussain), Tarp@wider.unu.edu (F. Tarp).
}

faced by the society in question. However, a subset of the articles is notably easier for wealthier societies to fulfill than for poorer societies. For instance, Articles 25 and 26 assert, respectively, that everyone has the right to an adequate standard of living and that everyone has the right to education, particularly at elementary levels.

Poor countries may confront enormous or even insurmountable (within short timeframes) obstacles in meeting these obligations of the UDHR, regardless of the collective desire of those with decision-making power within those societies (labeled dutybearers) to fulfill them. This gap between stated goals and circumstances on the ground makes it necessary to interpret the UDHR as an aspirational declaration whose tenets, under favorable circumstances, gradually become satisfied for an increasing share of the world's peoples and nations.

This same gap also generates a rationale for development assistance as an instrument to speed-up progress towards achieving the 
aspirations set forth in the UDHR and for the setting of clear goals, such as the Sustainable Development Goals (United Nations, 2017), to monitor progress. Many development institutions, notably the programs and specialized agencies of the UN, specifically link the rights set forth in the UDHR, their development programs, and attainment of the Sustainable Development Goals (SDGs). These links relate both to final goals and to the processes these institutions seek to put in place to attain development goals (such as the SDGs). The rights-based approach to development is meant to forge these links by specifically targeting 'the realization of human rights as laid down in the Universal Declaration' and by applying human rights principles as a guide to 'all development cooperation and programming in all sectors and in all phases of the programming process' (United Nations Children's Fund [UNICEF], 2004, p. 91).

In terms of principles, the UN Statement of Common Understanding of the UDHR (see United Nations Children's Fund, 2004, Appendix B) insists that human rights are (among other properties):

1. Indivisible: rights have equal status and cannot be ranked in a hierarchical order;

2. Inalienable: rights cannot be given up or taken away;

3. Interdependent: the realization of one right may depend, at least in part, on the realization of others; and

4. Equal: all human beings are entitled to their human rights.

This article is concerned with measurement of progress towards the attainment of human rights, which are inherently multidimensional. It falls within a large literature, both theoretical and empirical, related to the measurement of welfare across multiple dimensions of wellbeing (Alkire et al., 2015; Ravallion, 2016). It seeks to make three contributions. First, it assesses whether the main approach currently employed for measuring welfare across multiple dimensions, the multidimensional poverty index (MPI) of Alkire and Foster (2007) (henceforth AF) is, in fact, human rights-consistent. We assert that, while elegant and practical, the AF approach is inconsistent with human rights principles.

Second, an alternative approach based on first-order dominance (FOD) principles is presented and assessed (Arndt et al., 2012; Arndt, Østerdal, \& Siersbæk, 2016; Østerdal, 2010). The FOD approach is in line with the four human rights principles listed above.

Third, the AF and FOD approaches are applied to data for 26 African countries to determine welfare rankings around the year 2002 and for the most recent data point available (approximately the year 2012). The AF and FOD approaches generally provide similar country rankings in both time periods and both point broadly to progress over time. Divergences between the AF and the FOD approaches do occur, and provide significant additional information. The AF and FOD approaches are therefore best viewed as complementary methodologies that should be employed in tandem.

The remainder of this study is structured as follows. Section 2 presents the AF and FOD approaches and assesses them in the context of a rights-based development approach. Section 3 presents the application to welfare assessment for sub-Saharan Africa (SSA), while Section 4 concludes.

\section{The multidimensional poverty index and first-order dominance}

\subsection{Review of recent applications}

The United Nations Development Programme's (UNDP) MPI (Alkire \& Santos, 2010) and the underlying AF methodology
(Alkire \& Foster, 2007; Alkire et al., 2015) provide an important avenue for within- and cross-country multidimensional welfare comparisons and for comparisons over time. The MPI is relatively easy to compute from, for example, standard Demographic and Health Surveys (DHS) and/or UNICEF's Multiple Indicator Cluster Surveys (MICS) and is decomposable following the Foster, Greer, and Thorbecke (1984) class of poverty measures. Batana (2013) applies the AF method across 14 SSA countries to study poverty of women in the dimensions of assets, health, schooling, and empowerment. Alkire and Housseini (2014) present an extensive evaluation of multidimensional poverty in 37 SSA countries based on the 2014 MPI and on a modified index capturing severe deprivation. Analysis was extended to sub-regional decompositions and an assessment of poverty dynamics in 19 countries with consistent time-series.

FOD is also well-suited to within- and cross-country multidimensional welfare comparisons. It is, perhaps, particularly wellsuited to welfare comparisons through time. It was applied to Vietnam and Mozambique by Arndt et al. (2012), and FOD has since been applied to numerous countries, including the Democratic Republic of the Congo (DRC), Ghana, Nigeria, Tanzania, and Zambia. The results of the work on the countries just listed are presented in companion volumes examining growth and poverty in subSaharan Africa (Arndt, McKay, \& Tarp, 2016) and techniques in poverty measurement (Arndt \& Tarp, 2016). Also, Permanyer and Hussain (2017) applied FOD analysis to a cross-country study of 38 developing countries and, using the same set of indicators, compared their results to other multidimensional methodologies.

The next two subsections provide a brief review of each approach.

\subsection{Multidimensional poverty index}

A detailed development of the MPI can be found in Alkire et al. (2015). Briefly, the AF approach aggregates household or individual welfare statuses across multiple dimensions into a single index that provides insight into both the incidence and intensity of poverty. The approach depends upon dual cut-offs that identify dimension-specific deprivation thresholds and an acrossdimension threshold $(k)$, which specifies a share of weighted indicators. Households with weighted deprivation shares of at least $k$ are deemed poor and the proportion of such households yields the multidimensional poverty headcount $(H)$. The method further identifies the intensity of poverty $(A)$ as the average weighted deprivation share among the poor. The final AF poverty index is referred to as the adjusted headcount ratio $\left(M_{0}\right.$ or MPI), expressed as the product of the headcount ratio and the intensity of poverty:

$M_{0}=H \cdot A$

In this analysis, we follow the Alkire and Housseini (2014) MPI analysis of SSA and set the AF poverty threshold $(k)$ equal to onethird of weighted indicators.

\subsection{First-order dominance}

Østerdal (2010) and Arndt, Østerdal, and Siersbæk (2016) provide detailed treatments of FOD theory. A discussion of FOD in practice can be found in Arndt and Mahrt (2016). The FOD methodology builds upon earlier contributions to the dominance literature (Atkinson \& Bourguignon, 1982; Bérenger, Bresson, Makdissi, \& Yazbeck, 2013; Bourguignon \& Chakravarty, 2003; Cowell \& Victoria-Feser, 2007; Duclos \& Échevin, 2011; Duclos \& Makdissi, 2005; Duclos, Sahn, \& Younger, 2007, 2011; Gravel \& Mukhopadhyay, 2010; Gravel, Moyes, \& Tarroux, 2009; Lehmann, 1955; Levhari, Paroush, \& Peleg, 1975; Shaked \& Shanthikumar, 2007). 
Briefly, the FOD approach assumes that it is better to be not deprived than deprived in any welfare dimension. As with AF, FOD requires the identification of welfare indicators and the specification of an indicator specific threshold value that defines deprived versus not deprived. ${ }^{1}$ Hence, AF and FOD measures are both potentially sensitive to indicator thresholds. However, the FOD approach permits comparison of populations without indicator weights. And, in the absence of weights, FOD faces no need to specify a poverty line threshold (the $k$ in the AF approach).

Applying the FOD concept to two multidimensional discrete population distributions, $A$ and $B, A$ dominates $B$ if and only if it is possible to obtain distribution B from distribution A by moving probability mass from better to worse outcomes within A. Gravel and Moyes (2012) refer to these transfers of probability mass as 'increments in the indicators.'

Assume we have $n$ welfare dimensions and for each dimension a $0 / 1$ (deprived/not deprived) valued binary indicator is defined. With five binary indicators $(n=5)$, a total of $32\left(=2^{5}\right)$ unique welfare status combinations are possible for each basic unit of analysis, normally either an individual or a household. Let $a_{i}$ and $b_{i}$ be the shares of populations $A$ and $B$, respectively, with welfare status $i$. Let the variable $x_{i j}$ represent probability mass transfer from welfare status $i$ to welfare status $j$, where $j$ is an alias of $i$. Define $Z$ as the set of source-destination pairs $i j$ that move probability from a preferred welfare status $i(i=1, \ldots 32)$ to an inferior welfare status $j$.

A welfare status $i$ is preferred to status $j$ if and only if status $i$ is at least as good as status $j$ in all dimensions and better in at least one dimension. For example, status $(1,1,1,1,1)$, indicating not deprived in all dimensions, is preferred to all other welfare statuses. Similarly, status $(0,0,0,0,0)$, indicating deprived in all dimensions, is least preferred. Moving to more complex cases, status $(1,1,1,0,0)$ is preferred to status $(0,1,1,0,0)$ because the latter status can be obtained from the former by removing the not deprived status in dimension one, which makes the unit of analysis unambiguously worse-off. The criterion is strict. Status $(0,1,1,1,1)$ is not unambiguously better than status $(1,0,0,0,0)$.

Under these conditions, population A dominates population $\mathrm{B}$ (i.e., FOD is found) if there exist $x_{i j}$ with:

$x_{i j} \geqslant 0, \quad x_{i j} \leqslant 1, \quad x_{i i}=0$, such that $a_{i}+\sum_{j i \in Z} x_{j i}-\sum_{i j \in Z} x_{i j}=b_{i} \forall i$.

Mosler and Scarsini (1991) and Dyckerhoff and Mosler (1997) note that the system of equations described in (2) corresponds to a linear program. Arndt et al. (2012) and Arndt and Mahrt (2016) provide an empirical implementation of the linear programmingbased method for checking multidimensional FOD with up to seven binary deprivation indicators.

While FOD analysis allows for comparison across populations without imposing subjective restrictions, the FOD criterion sometimes leads to indeterminate outcomes, meaning that population A does not dominate population B and population B does not dominate population A. Satisfaction of Eq. (2) also gives no sense of the extent of domination. We label a single test of whether population A dominates population B as static FOD analysis. Arndt et al. (2012) suggest supplementing static FOD analysis with FOD analysis conducted on repeated bootstrap samples drawn from each population (Efron, 1979). Where appropriate, bootstrapping is conducted taking the survey design (strata and cluster) into account. The subsequent FOD results can be interpreted as a measure of

\footnotetext{
${ }^{1}$ Multiple thresholds for a single indicator are possible but quickly suffer the curse of dimensionality. In practice, both AF and FOD typically rely on binary indicators.

2 Thanks to an anonymous referee for pointing this out.
}

likelihood of domination providing substantially more information than FOD in the static case. Furthermore, one can define a measure of net-domination (the average frequency that an area dominates all other populations minus the average frequency that the area is dominated by all other populations), which can be used as a basis to rank populations (Copeland, 1951).

\subsection{Assessment}

The AF and FOD approaches are defined precisely in mathematical terms providing a set of rigorous properties. In contrast, there is no formal mathematical expression of the principles in the UDHR. Nevertheless, comparing properties with principles, the FOD approach conforms better to human rights concepts than the approach propounded by AF. If we view indicators as basic rights such as a right to a primary school education, a right to safe water, a right to adequate sanitation, and so forth, then the weighting scheme integral to AF becomes problematic. Under AF, the indicators (rights) are not indivisible in that they are explicitly ranked via the weighting scheme. Under AF, the indicators (rights) are not inalienable in that it is perfectly possible to be judged betteroff even after a population-wide shift from not deprived to being deprived in one indicator if there are gains in other indicators. Under AF, the indicators (rights) are not equal in that welfare losses among worse-off subgroups can be outweighed by gains among better-off subgroups resulting in measured progress. Overall, when focusing on distributions of populations as classified by deprived or not deprived status for multiple binary indicators (rights), the AF approach violates three of the four principles listed in Section 1.

In contrast, the FOD conforms well. Under FOD, indicators (rights) are indivisible in that no weighting of any sort is applied. Under FOD, indicators (rights) are inalienable in that, when population A FOD population B, the distribution of indicators (rights) in population A can be obtained from population B only by moving weight from less preferred to more preferred states within population B. Finally, under FOD, indicators are equal in that for progress to be deemed to have occurred, it must occur across the full distribution of welfare outcomes. To take just one example, population $\mathrm{A}$ will never FOD population B if the share of population A in status $(0,0,0,0,0)$ is greater than the corresponding share in population B. More generally, welfare gains among better-off groups never offset welfare losses among worse-off groups.

These differential properties can lead to dissimilar results by approach for the same indicators and indicator thresholds. A substantial difference is that FOD may result in indeterminate outcomes while AF will always generate a welfare ranking (though these might not be statistically significant). Consider a simple example with two households and three indicators where 0/1 denotes deprived/not deprived. Under FOD, dominance cannot be established between two households with welfare outcomes such as $(0,1,0)$ and $(1,0,1)$. This occurs because no assumptions are made about the relative importance of each dimension, consistent with human rights principles. With the AF method, a result is always obtained, but the result depends upon how weights are assigned. With equal weighting across indicators, the second household attains superior welfare compared to the first, while the weighting scheme $(0.2,0.6,0.2)$ suggests the first household is associated with greater welfare. Put differently, fidelity to very general human rights principles, as in FOD, may come at a cost in terms of determinacy of outcomes. At the same time, the determinacy of outcomes in AF comes at the cost of violating rights-based principles in the evaluation of welfare.

With respect to the interdependence principle, both AF and FOD are effectively agnostic in that neither make any attempt to capture interdependence. This is appropriate. In the UN Statement of Common Understanding (United Nations Children's Fund, 2004, 
Appendix B), interdependence is prospective. The example adduced indicates that the "realization of the right to health may depend, in certain circumstances, on realization of the right to education or information" (p. 92). Given this example, one could argue that a household or individual is prospectively better off once the education right is realized because prospects for realizing other rights, such as health, might be improved (in certain circumstances). However, both AF and FOD seek to measure welfare at a given moment (or snapshot) in time. Welfare dynamics are studied through multiple snapshots (in practice, multiple comparable survey rounds through time as in the DHS) that meter actual, as opposed to prospective, progress.

Note the distinction between the interdependence principle and the concept of complements in utilitarian welfare theory. In the latter, two goods, such as tea and milk, may be complements because they are preferred to be enjoyed together. In contrast, from a welfare ranking perspective with respect to realization of rights, rights are neither substitutes nor complements. If the pattern of development in country A is such that two rights are frequently realized in tandem, there is no automatic linkage to a notion of rights preference or inferences with respect to the form of a social welfare function, not least because the pattern of development may depend heavily on supply side factors or ad hoc decisions by duty-bearers (as opposed to revealing consistent population-wide preferences across rights). In short, rights are not analogous to maize and cassava (substitutes) or tea and milk (complements) in the utilitarian conception. More generally, measures, such as Atkinson and Bourguignon (1982), that "impose different assumptions about the form" (p. 184) of the social welfare function, such as sign conditions on derivatives of the social welfare function, are not rights-consistent. ${ }^{3}$

Finally, there are important differences in interpretation of $\mathrm{AF}$ and FOD results. AF is a distance measure with a cardinal interpretation. Static FOD is a binary comparison with an ordinal interpretation (i.e., A dominates B). The application of the bootstrap produces a large number of binary comparisons. By counting the number of dominations recorded and then applying an affine transformation, a Copeland index can be created. This index reflects an underlying (cardinal) count of the number of dominations but does not reflect any particular magnitude of welfare change. Indeed, as will be seen in Section 3, it is possible for country A to register strong progress through time by FOD even though the shares of the population not deprived in the indicators in focus improve by small magnitudes. A similar logic applies to comparisons across countries.There are also practical differences in the application of AF and FOD. These are best discussed in the context of an application.

\section{Application to sub-Saharan Africa}

Sub-Saharan African economies have seen relatively high growth rates during the last 20 years (IMF, 2013). The extent to which growth has improved the living conditions for those living in poverty is less clear; thus, the Bourguignon (2004) poverty, growth, inequality triangle continues to be widely debated (e.g., Arndt, McKay, \& Tarp, 2016; Fosu, 2015; Thorbecke, 2013). Here we frame the first aspect of the triangle, poverty, in the context of attaining basic human rights, which is inherently nonmonetary and multidimensional in nature. The expansion of DHS and MICS over the last two decades has greatly enhanced the potential for consistent multidimensional poverty analysis across countries

\footnotetext{
${ }^{3}$ Interpretation of the interdependence principle is tricky. Thanks to an anonymous reviewer who, while not necessarily endorsing the interpretation provided here, obliged the authors to think carefully and systematically in this domain.
}

and time. Yet, relatively few studies define a consistent set of welfare measures to assess multidimensional wellbeing across African countries. Sahn and Stifel (2000) apply factor analysis of household socioeconomic characteristics in 15 SSA countries. Booysen, Van Der Berg, Burger, Von Maltitz, and Du Rand (2008) extend this work for seven SSA countries, employing multiple correspondence rather than factor analysis. As mentioned, Batana (2013) applies the AF method in an assessment of women's wellbeing in 14 SSA countries. And, in the most comprehensive analysis, Alkire and Housseini (2014) present an evaluation of 37 SSA countries based on the 2014 MPI as well as a modified index capturing severe deprivation.

We pursue a double goal of first contributing to this literature by identifying welfare rankings of 26 SSA countries and evaluating the extent to which broad-based growth in welfare and changes to welfare rankings have occurred over time. Second, we consider the ability of the FOD and AF methodologies to assess multidimensional poverty from a rights-based perspective. As noted, satisfying the tenets of the UDHR is an ongoing process and this is particularly so in SSA, where access to minimal standards of living such as basic sanitation, clean drinking water, adequate shelter, participation via access to information, and primary education continues to be out of reach for sizeable portions of the population. Being able to assess multidimensional poverty while adhering to basic rights principles (inalienability, indivisibility, interdependence, and equality) is therefore particularly pertinent in the SSA context.

\subsection{Data}

The DHS provide relevant wellbeing data using a harmonized survey structure across most of the 26 SSA countries examined in this study (DHS, 2016). Although not all countries in SSA are included, the investigated countries represent 84 per cent of the population. Two DHS surveys were used for each country, representing a year close to $2002\left(t=t_{1}\right)$ and another year close to $2012\left(t=t_{2}\right)$, enabling us to monitor welfare changes over time within a given country. The DHS were not available in both years for South Africa and the DRC. As alternatives, the 2002 and 2012 national General Household Surveys (GHS) provide the data for South Africa (Statistics South Africa, 2003, 2013) and the 2001 MICS provides the first round of the DRC data (RDdC, 2002). The MICS and DHS are highly compatible due to a close collaboration to ensure that survey tools and methodologies are harmonized and comparable.

Sample sizes for each country and year are displayed in Table 1. The median first and last survey years are 2003 and 2012, respectively. The sample size in the second round of surveys is typically higher (median 13,300) than in the first round (median 8100), but with major variations across countries (approximately between 5000 and 38,000 observations in each round).

\subsection{Indicator definitions}

Multidimensional analysis in this study is based upon five binary welfare indicators. The choice of indicators draws upon the widely-applied Bristol Indicators (Gordon, Nandy, Pantazis, Pemberton, \& Townsend, 2003) and aims to cover basic aspects of wellbeing in a developing country setting-specifically: drinking water, sanitation, shelter, communication, and education.

For each indicator, a household is either deemed to be deprived and the indicator is assigned the value 0 , or the household is not deprived and the indicator takes the value 1 . Indicator thresholds are selected based on careful consideration of three factors. First, following existing tradition in defining standards of wellbeing brings relevance and context to threshold choices. Furthermore, following tradition provides consistency across time, space, and 
Table 1

Survey year, sample size, and population size.

\begin{tabular}{|c|c|c|c|c|c|c|c|}
\hline & \multicolumn{3}{|c|}{ Survey year } & \multicolumn{3}{|c|}{ Sample size } & \multirow{2}{*}{$\begin{array}{l}\text { Population (millions) } \\
2012\end{array}$} \\
\hline & $t_{1}$ & $t_{2}$ & Range (years) & $t_{1}$ & $t_{2}$ & Total & \\
\hline Benin (BEN) & 2001 & 2011 & 10 & 5756 & 17,422 & 23,178 & 10.0 \\
\hline Burkina Faso (BFA) & 2003 & 2010 & 7 & 9075 & 14,410 & 23,485 & 16.6 \\
\hline Cameroon (CMR) & 2004 & 2011 & 7 & 10,435 & 14,177 & 24,612 & 21.7 \\
\hline Chad (TCD) & 2004 & 2014 & 10 & 5358 & 17,108 & 22,466 & 12.7 \\
\hline Congo, Dem. Rep. (DRC) ${ }^{b}$ & 2001 & 2013 & 12 & 8622 & 18,144 & 26,766 & 70.3 \\
\hline Congo, Rep. (COG) & 2005 & 2011 & 6 & 5870 & 11,610 & 17,480 & 4.3 \\
\hline Côte d'Ivoire (CIV) ${ }^{\mathrm{a}}$ & 2005 & 2011 & 6 & 4348 & 9649 & 13,997 & 21.1 \\
\hline Ethiopia (ETH) & 2000 & 2011 & 11 & 14,059 & 16,678 & 30,737 & 92.2 \\
\hline Gabon (GAB) & 2000 & 2012 & 12 & 6171 & 9716 & 15,887 & 1.6 \\
\hline Ghana (GHA) & 2003 & 2014 & 11 & 6233 & 11,834 & 18,067 & 25.5 \\
\hline Guinea (GIN) & 2005 & 2012 & 7 & 6242 & 7103 & 13,345 & 11.6 \\
\hline Kenya (KEN) & 2003 & 2014 & 11 & 8532 & 36,396 & 44,928 & 42.5 \\
\hline Lesotho (LSO) & 2004 & 2014 & 10 & 8561 & 9402 & 17,963 & 2.1 \\
\hline Madagascar (MDG) & 2004 & 2008 & 4 & 8412 & 17,832 & 26,244 & 22.3 \\
\hline Malawi (MWI) & 2000 & 2010 & 10 & 13,648 & 24,789 & 38,437 & 15.7 \\
\hline Mali (MLI) & 2001 & 2012 & 11 & 12,267 & 10,104 & 22,371 & 16.1 \\
\hline Mozambique (MOZ) & 2003 & 2011 & 8 & 12,295 & 13,919 & 26,214 & 25.7 \\
\hline Namibia (NAM) & 2000 & 2013 & 13 & 6342 & 9815 & 16,157 & 2.3 \\
\hline Nigeria (NGA) & 2003 & 2013 & 10 & 7162 & 38,361 & 45,523 & 168.2 \\
\hline Rwanda (RWA) & 2000 & 2014 & 14 & 9650 & 12,677 & 22,327 & 10.8 \\
\hline Senegal (SEN) & 2005 & 2012 & 7 & 7359 & 8406 & 15,765 & 13.8 \\
\hline South Africa $(\mathrm{ZAF})^{\mathrm{c}}$ & 2002 & 2012 & 10 & 26,169 & 24,856 & 51,025 & 52.4 \\
\hline Tanzania (TZA) & 2003 & 2011 & 8 & 6484 & 10,019 & 16,503 & 48.6 \\
\hline Uganda (UGA) & 2000 & 2011 & 11 & 7847 & 9028 & 16,875 & 35.4 \\
\hline Zambia (ZMB) & 2001 & 2013 & 12 & 7110 & 15,868 & 22,978 & 14.8 \\
\hline Zimbabwe (ZWE) & 2005 & 2010 & 5 & 9266 & 9756 & 19,022 & 14.6 \\
\hline Median & 2003 & 2012 & 10 & 8130 & 13,298 & 22,419 & 16.4 \\
\hline
\end{tabular}

Notes: Source: own calculations based on DHS standard surveys, except where noted.

a Côte d'Ivoire 2005, Tanzania 2003, Tanzania 2011 DHS AIS surveys.

b DRC 2001 MICS.

c South Africa 2002, 2012 GHS.

d World Bank (2016b).

methodologies, which allows for more comparability in monitoring progress. Second, threshold choices must conform to the nature of the available survey data. Even within surveys designed to be harmonized across time and space, response categories may vary and thus constrain the number of possible consistent thresholds. In studies across nations and across time, such data restrictions can be considerable. Finally, to provide informative comparisons, thresholds are chosen such that they fall in the heart of the distribution of outcomes. Welfare thresholds set such that the large majority of the population is deprived or not deprived may conform to the first two criteria, but provide little information in welfare comparisons. These three criteria are restrictive, and, as a result, threshold choices are, in practice, relatively few.

Surveys such as the DHS, devoted to monitoring various aspects of welfare, primarily provide categorical data. It is possible with the FOD methodology to make use of the broader range of information provided in these surveys by either using the full range of outcomes or by defining categorical indicators with more than two values. With five binary indicators, the combination of possible welfare outcomes is $2^{5}=32$. If instead we define three categories per indicator, the number of possible combinations increases to $3^{5}=243$. Data requirements quickly become prohibitive as the number of observations occupying combinations of welfare outcomes may become quite small. This 'curse of dimensionality' is even more pronounced when considering subpopulations within a country such as regions or age groups. A further consideration in deviating from binary indicators involves the evolving nature of survey questionnaires. As noted above, inconsistent survey response options make it challenging to develop robust binary comparisons; this issue is even more restrictive when attempting to identify multiple categories through time and across countries.

\subsubsection{Water}

A household is not deprived in the water indicator when it obtains drinking water from a safe source (tap, pipe, public standpipe, tube-well, borehole, covered dug well, rainwater, or bottled/ sachet water). For monitoring progress in achieving the Millennium Development Goals (MDGs), UNICEF and the World Health Organization (WHO) developed a commonly adopted definition of improved water sources that also classifies covered springs as safe (United Nations Children's Fund \& World Health Organization, 2015). However, early rounds of the DHS do not distinguish between protected and unprotected springs. To maintain consistency over time and to avoid confusing progress with households simply shifting between changing survey categories, our definition classifies all springs as a deprivation.

\subsubsection{Sanitation}

A household is considered not deprived in sanitation when the household has access to sanitation facilities and deprived when the household relies upon buckets, hanging latrines, or open defecation. Our definition differs from that of UNICEF and WHO, which specify deprivation in sanitation to include shared facilities, pit latrines without a slab, and facilities that flush or pour to somewhere other than a sewer system, septic tank, or pit latrine. Four issues in $t_{1}$ surveys prevent us from adopting this widelyaccepted definition. First, in $t_{1}$, improved pit latrines appear to refer to ventilated improved pit latrines in some instances and to any improved pit latrine in others. Second, there is no distinction between traditional pit latrines with and without a slab. Third, the surveys do not specify whether facilities flush to a sewer system, septic tank, or pit latrine. Finally, the 2001 DRC MICS and South African GHS surveys do not specify whether facilities are shared. Consequently, we can only determine with consistency 
and certainty whether households use any kind of flush toilet or whether households use no facilities. As the latter deprivation more closely corresponds to both policy goals and severe deprivation indicators in other studies, this is the definition adopted here (see Alkire \& Housseini, 2014; Gordon et al., 2003).

\subsubsection{Shelter}

Adequate flooring is often adopted as a proxy for housing quality (see for example the UNDP's MPI (United Nations Development Programme, 2016b)). In this study, we follow guidelines for evaluating the SDG target 11.1 pertaining to adequate housing and identify a household to be not deprived if the floor of its dwelling is constructed from permanent material and deprived when the floor is derived from non-permanent material (United Nations Statistics Division, 2017). Solid floors primarily include cement and brick, and to a lesser degree tile, carpet, vinyl, wood, and parquet. Inadequate flooring mainly includes earth, sand, dung, and palm/bamboo. The South Africa GHS does not report flooring material and consequently we define shelter deprivation in terms of wall quality instead.

\subsubsection{Communication}

The inclusion of access to information and communication in the SDGs highlights their critical role in 'sustained, inclusive and equitable economic growth and sustainable development, competitiveness, access to information and knowledge, poverty eradication and social inclusion' (United Nations General Assembly, 2015, p. 4). Our communication indicator measures radio, television, and telephone (cellular or fixed) ownership. ${ }^{4}$ If the household does not possess any of these communication methods, it is deemed deprived.

\subsubsection{Education}

As mentioned, the UDHR identifies education as a basic human right. It is also an important indicator of the human capital level within a household. The UNDP's MPI and the MDG goal 2 both prioritize completion of primary education (United Nations, 2015; United Nations Development Programme, 2016b), while the SDG target 4.1 strives for both primary and secondary completion (United Nations Statistics Division, 2017). However, even primary completion rates remain relatively low in many SSA countries. In more than half of the countries considered in this study, less than 10 per cent of the adult sample completed secondary school. We focus on primary education to achieve relevance while defining a threshold that cuts through an informative range of the distribution across both countries and time. A household is not deprived in education if one or more household members have completed at least six years of schooling. Among the countries in this study, six years of schooling is the median number of school years required to complete primary school.

\footnotetext{
${ }^{4}$ While the SDGs emphasize the importance of internet access, information on internet access is only collected in select country surveys in later years. However, a sufficiently high correlation exists between mobile phone ownership and internet access such that we do not feel this presents a deficiency in the communication indicator. For instance, in countries for which the data are available, the share of households with internet access that did not also have a mobile phone ranged from 0 per cent in Côte d'Ivoire and Burkina Faso to 6 per cent in Benin, with most countries at 1 per cent or less.

5 The 2000 Malawi DHS does not report phone possession. An examination of the 2004 Malawi DHS suggests that phone ownership is highly related to radio ownership. In a sample of 13,664 households that do not own a radio, only 18 possess a phone. The 2001 DRC MICS does not report phone or television ownership in rural areas. The 2007 DRC DHS, with a sample of 5189 households, indicates that 3482 rural households do not own a radio but only three of these households own a television and only 27 own a mobile or fixed phone. Therefore, we do not consider this lack of reporting to be a significant limitation.
}

\subsubsection{Indicator sensitivity}

As noted above, it is not possible to define water and sanitation thresholds in $t_{1}$ according to commonly applied international standards. To evaluate the sensitivity of spatial outcomes to water and sanitation thresholds, we specify alternative thresholds in $t_{2}$ that correspond to the UNICEF and WHO definitions of improved water and sanitation described above. The improved sanitation indicator is defined with and without considering whether the facility is shared. Sensitivity to indicator thresholds in FOD analysis is also explored by Ajakaiye, Jerome, Olaniyan, Mahrt, and Alaba (2016), Arndt, Lerayo, Mahrt, and Tarp (2016), and Mahrt and Masumbu (2016) in applications to Nigeria, Tanzania, and Zambia respectively. The authors find that FOD temporal dynamics can be sensitive to indicator thresholds, while spatial patterns are typically more robust.

\subsection{Results}

3.3.1. Welfare indicator averages and the joint distribution of welfare Overall, we see progress in most countries for most indicators, but backsliding within welfare dimensions is also observed (Table 2). Three countries experience welfare reductions in two dimensions: Côte d'Ivoire and Nigeria (sanitation and shelter) and Rwanda (water and sanitation). Seven countries experience backsliding in one indicator: Cameroon, the Republic of the Congo, Gabon, and Tanzania (sanitation); DRC and Madagascar (shelter); and Burkina Faso (education). The remaining 16 countries see progress on average in all five dimensions. The degree of progress varies substantially by dimension and area. For example, Ethiopia, which starts from a very low base, achieves impressive progress in every dimension, with the percentage of the population not deprived in water, sanitation, and communication more than doubling. In contrast, South Africa, which starts from a high base, achieves relatively modest gains in every indicator. Considering the 26 SSA countries in aggregate, there is no backsliding (of weighted averages) in any dimension. Population-weighted averages improve for the aggregate in access to safe water (47-61 per cent), sanitation (68-75 per cent), shelter (43-45 per cent), communication access (62-79 per cent), and education (62-70 per cent).

We now focus on the joint welfare distribution at the household level using two countries as examples. The complete joint distribution of welfare outcomes for Nigeria and Uganda are presented in Table 3. Comparing the distributions for period $t_{1}$, Nigeria has a significantly higher rate of those not deprived in any of the five indicators (24.7 versus 12.2 per cent), but only a slightly lower share deprived in all indicators (3.0 versus 3.2 per cent). Most of the distribution involves intermediate outcomes.

Without imposing weights, the relative importance of dimensions cannot be ranked. Thus, the relative welfare of a household deprived only in sanitation compared to a household deprived only in water or even compared to a household deprived in all dimensions except sanitation, is indeterminate. If we simply count the number of indicators for which a household is not deprived, giving each indicator equal weight, the average number of positive welfare outcomes in Nigeria is 3.3 and 3.6, compared to 2.8 and 3.4 in Uganda, in $t_{1}$ and $t_{2}$ respectively. However, imposing alternative weighting schemes may reverse estimated relative welfare. For example, placing higher priority on water and sanitation outcomes leads, in Nigeria, to attaining fewer positive outcomes (3.0 and 3.4) than Uganda ( 3.2 and 3.8) in $t_{1}$ and $t_{2}$. While imposing weights facilitates comparability of outcomes, it violates the principle of indivisibility. Furthermore, outcomes from weighted analysis have the undesirable property of depending on the choice of weights. The FOD approach applied in this study eliminates the need for weighting schemes producing conclusions that are both robust to the choice of weights and consistent with the rights-based approach. 
Table 2

Individuals not deprived in welfare indicators, in $t_{1}$ and $t_{2}$ (per cent).

\begin{tabular}{|c|c|c|c|c|c|c|c|c|c|c|}
\hline & \multicolumn{2}{|c|}{ Water } & \multicolumn{2}{|c|}{ Sanitation } & \multicolumn{2}{|c|}{ Shelter } & \multicolumn{2}{|c|}{ Communication } & \multicolumn{2}{|c|}{ Education } \\
\hline & $t_{1}$ & $t_{2}$ & $t_{1}$ & $t_{2}$ & $t_{1}$ & $t_{2}$ & $t_{1}$ & $t_{2}$ & $t_{1}$ & $t_{2}$ \\
\hline Benin & 66 & 75 & 32 & 41 & 59 & 61 & 77 & 86 & 39 & 56 \\
\hline Burkina Faso & 58 & 76 & 30 & 36 & 40 & 44 & 68 & 82 & 34 & 32 \\
\hline Cameroon & 59 & 63 & 93 & 92 & 49 & 54 & 68 & 81 & 70 & 74 \\
\hline Chad & 36 & 56 & 28 & 30 & 5 & 9 & 41 & 71 & 28 & 42 \\
\hline Congo, D.R. & 28 & 34 & 81 & 87 & 21 & 20 & 34 & 61 & 66 & 83 \\
\hline Congo, Rep. & 58 & 73 & 90 & 90 & 58 & 67 & 64 & 90 & 90 & 90 \\
\hline Côte d'Ivoire & 69 & 78 & 69 & 66 & 82 & 82 & 74 & 90 & 57 & 59 \\
\hline Ethiopia & 19 & 42 & 18 & 62 & 7 & 11 & 22 & 49 & 23 & 44 \\
\hline Gabon & 79 & 89 & 98 & 91 & 78 & 88 & 82 & 97 & 85 & 90 \\
\hline Ghana & 66 & 88 & 74 & 79 & 86 & 93 & 75 & 93 & 74 & 83 \\
\hline Guinea & 62 & 75 & 72 & 83 & 46 & 55 & 69 & 84 & 37 & 50 \\
\hline Kenya & 42 & 57 & 81 & 87 & 34 & 45 & 76 & 91 & 84 & 90 \\
\hline Lesotho & 73 & 77 & 56 & 71 & 59 & 65 & 58 & 91 & 85 & 90 \\
\hline Madagascar & 32 & 37 & 54 & 56 & 40 & 37 & 61 & 65 & 39 & 41 \\
\hline Malawi & 66 & 79 & 84 & 90 & 20 & 24 & 59 & 66 & 58 & 68 \\
\hline Mali & 44 & 66 & 79 & 88 & 21 & 27 & 75 & 90 & 23 & 40 \\
\hline Mozambique & 46 & 53 & 53 & 61 & 26 & 27 & 61 & 67 & 35 & 49 \\
\hline Namibia & 77 & 84 & 41 & 49 & 42 & 56 & 76 & 95 & 86 & 91 \\
\hline Nigeria & 40 & 63 & 75 & 70 & 65 & 61 & 76 & 89 & 72 & 73 \\
\hline Rwanda & 42 & 40 & 97 & 97 & 15 & 25 & 40 & 77 & 50 & 63 \\
\hline Senegal & 69 & 78 & 78 & 82 & 65 & 73 & 91 & 98 & 43 & 62 \\
\hline South Africa & 86 & 93 & 86 & 95 & 81 & 89 & 88 & 99 & 96 & 97 \\
\hline Tanzania & 51 & 54 & 89 & 86 & 27 & 32 & 61 & 80 & 85 & 88 \\
\hline Uganda & 52 & 70 & 85 & 90 & 20 & 27 & 56 & 81 & 66 & 72 \\
\hline Zambia & 53 & 63 & 73 & 84 & 39 & 44 & 50 & 81 & 81 & 86 \\
\hline Zimbabwe & 75 & 76 & 68 & 71 & 66 & 69 & 53 & 73 & 94 & 96 \\
\hline
\end{tabular}

Source: see Table 1.

\subsubsection{Temporal FOD}

Temporal FOD analysis provides evidence of multidimensional welfare performance over time. FOD tests lead to three possible outcomes for each country: $t_{2}$ dominates $t_{1}, t_{1}$ dominates $t_{2}$, or no dominance. Static outcomes derived from the actual survey data provide little information in the case of indeterminacy and no information on the extent of domination. Determining the frequency of domination across 100 bootstrap samples partially fills these gaps. ${ }^{6}$

Table 4 presents static and bootstrap FOD results. Sixteen countries experienced broad-based progress in welfare over time and exhibited a high degree of correlation between static and bootstrap outcomes. The average frequency (normalized to the interval $[0,1]$ henceforth) of domination in the bootstrap is 0.92 when static FOD occurs. Eight countries achieved FOD in all 100 bootstraps (Ethiopia, Guinea, Kenya, Mali, Namibia, South Africa, Uganda, and Zambia) and six achieved FOD in more than 80 bootstraps (Ghana, Malawi, Senegal, Benin, Lesotho, and Chad). Despite static FOD, bootstrap sampling provides weaker likelihood of advancement in Mozambique (0.57) and Zimbabwe (0.48), though both periods of analysis cover a shorter time span of eight and five years, respectively.

The average bootstrap frequency of domination for the 10 countries with indeterminate static FOD is only 0.08 . Though a few countries have weak evidence of advancement, Cameroon (0.20), the DRC (0.17) and Burkina Faso (0.14), in most the frequencies are very small (Madagascar, Tanzania, the Republic of Congo, Côte d'Ivoire, and Rwanda) or zero (Gabon and Nigeria). Consistent with generally positive trends becoming more easily identifiable over longer periods of time, the median timespan

\footnotetext{
${ }^{6}$ In practice, the number of bootstrap iterations can be chosen to be sufficiently large to generate a complete ranking of the populations being compared. As will be discussed, cases with slight differences in the frequency of domination provide a weak basis for rankings. A greater number of bootstrap iterations does not improve this basis as it reflects a paucity of differentiating information (using the FOD criteria) in the underlying data.
}

for countries with static FOD is 10 years compared to 7.5 for countries without static FOD. In no case (static or bootstrap) did the first period dominate the second, indicating no broad-based decline in welfare over time for any of the 26 analyzed SSA nations.

In measuring broad-based progress, temporal FOD adheres to basic rights principles in that if any segment of the population (equality) is regressing in any dimension (inalienability), FOD will not register advancement. All cases of temporal stagnation are accompanied by backsliding in at least one welfare indicator (see Table 2). Of note are Cameroon and Gabon, in which stagnation was driven by diminished access to sanitation facilities. Despite this reduction, both countries remain at the top in terms of second-period sanitation welfare. Furthermore, both countries achieved considerable progress in all other indicators. These results draw attention to the need to interpret FOD outcomes appropriately. FOD stagnation does not necessarily imply a lack of any progress. Instead, it indicates that the progress was not achieved throughout the distribution and among all indicators. Overall, we find ample evidence of robust multidimensional progress in SSA and no evidence of multidimensional regress over the period analyzed.

\subsubsection{Spatial FOD}

As with temporal comparisons, spatial FOD tests are conducted using both the static and bootstrapping approaches. Spatial FOD outcomes are the result of country-by-country comparisons, whereby country A dominates country B, country B dominates country A, or neither country dominates. Tables 5 and 6 present bootstrap frequencies that a given row country first-order dominates the corresponding column country. Static FOD exists except when the bootstrap entry is underlined. Generally static FOD is observed where there are higher probabilities of bootstrap FOD (between 0.37 and 1) compared to no static FOD (between 0 and 0.45 ). Row averages represent the frequency that the row country dominates all other countries while column averages indicate the 
Table 3

Sample joint distribution of welfare indicators for Nigeria and Uganda, $t_{1}$ and $t_{2}$.

\begin{tabular}{|c|c|c|c|c|c|c|c|c|c|c|c|}
\hline \multirow[t]{3}{*}{ Outcome ranking } & \multicolumn{5}{|c|}{${\text { Welfare indicator combinations }{ }^{\mathrm{a}}}^{\mathrm{a}}$} & \multicolumn{6}{|c|}{$\underline{\text { Distribution (per cent) }}$} \\
\hline & \multirow[t]{2}{*}{1} & \multirow[t]{2}{*}{2} & \multirow[t]{2}{*}{3} & \multirow[t]{2}{*}{4} & \multirow[t]{2}{*}{5} & \multicolumn{3}{|c|}{ Nigeria } & \multicolumn{3}{|c|}{ Uganda } \\
\hline & & & & & & $\mathrm{t}_{1}$ & $\mathrm{t}_{2}$ & Change & $\mathrm{t}_{1}$ & $\mathrm{t}_{2}$ & Change \\
\hline Worst outcome & 0 & 0 & 0 & 0 & 0 & 3.0 & 2.2 & -0.7 & 3.2 & 1.1 & -2.1 \\
\hline Intermediate welfare combinations. & 0 & 0 & 0 & 0 & 1 & 2.4 & 1.0 & -1.4 & 2.2 & 0.3 & -1.9 \\
\hline \multirow{29}{*}{ Combinations are not always rankable. } & 0 & 0 & 0 & 1 & 0 & 3.0 & 3.4 & 0.4 & 1.0 & 0.5 & -0.5 \\
\hline & 0 & 0 & 0 & 1 & 1 & 3.4 & 4.2 & 0.8 & 1.3 & 0.7 & -0.6 \\
\hline & 0 & 0 & 1 & 0 & 0 & 0.6 & 0.3 & -0.3 & 0.1 & 0.0 & -0.1 \\
\hline & 0 & 0 & 1 & 0 & 1 & 1.4 & 0.4 & -1.0 & 0.0 & 0.0 & 0.0 \\
\hline & 0 & 0 & 1 & 1 & 0 & 0.6 & 0.9 & 0.3 & 0.0 & 0.0 & 0.0 \\
\hline & 0 & 0 & 1 & 1 & 1 & 4.1 & 4.1 & 0.0 & 0.0 & 0.1 & 0.1 \\
\hline & 0 & 1 & 0 & 0 & 0 & 4.0 & 1.5 & -2.6 & 9.0 & 2.4 & -6.5 \\
\hline & 0 & 1 & 0 & 0 & 1 & 2.1 & 0.6 & -1.5 & 7.7 & 2.3 & -5.5 \\
\hline & 0 & 1 & 0 & 1 & 0 & 4.6 & 4.4 & -0.2 & 5.5 & 5.1 & -0.3 \\
\hline & 0 & 1 & 0 & 1 & 1 & 5.1 & 4.3 & -0.8 & 13.2 & 12.2 & -1.0 \\
\hline & 0 & 1 & 1 & 0 & 0 & 1.3 & 0.4 & -0.8 & 0.1 & 0.1 & 0.0 \\
\hline & 0 & 1 & 1 & 0 & 1 & 2.5 & 0.2 & -2.2 & 0.7 & 0.2 & -0.5 \\
\hline & 0 & 1 & 1 & 1 & 0 & 3.9 & 2.4 & -1.5 & 0.3 & 0.5 & 0.2 \\
\hline & 0 & 1 & 1 & 1 & 1 & 17.7 & 6.4 & -11.2 & 3.7 & 4.4 & 0.7 \\
\hline & 1 & 0 & 0 & 0 & 0 & 0.9 & 1.0 & 0.2 & 3.4 & 2.7 & -0.7 \\
\hline & 1 & 0 & 0 & 0 & 1 & 0.6 & 0.5 & -0.2 & 2.2 & 1.2 & -1.0 \\
\hline & 1 & 0 & 0 & 1 & 0 & 0.5 & 1.7 & 1.2 & 0.6 & 1.2 & 0.5 \\
\hline & 1 & 0 & 0 & 1 & 1 & 1.0 & 2.6 & 1.6 & 1.1 & 1.8 & 0.6 \\
\hline & 1 & 0 & 1 & 0 & 0 & 0.2 & 0.1 & 0.0 & 0.0 & 0.0 & 0.0 \\
\hline & 1 & 0 & 1 & 0 & 1 & 0.7 & 0.4 & -0.3 & 0.1 & 0.0 & -0.1 \\
\hline & 1 & 0 & 1 & 1 & 0 & 0.2 & 0.7 & 0.5 & 0.0 & 0.0 & 0.0 \\
\hline & 1 & 0 & 1 & 1 & 1 & 2.0 & 6.7 & 4.7 & 0.1 & 0.2 & 0.1 \\
\hline & 1 & 1 & 0 & 0 & 0 & 1.4 & 1.2 & -0.2 & 5.6 & 4.0 & -1.6 \\
\hline & 1 & 1 & 0 & 0 & 1 & 0.5 & 0.6 & 0.1 & 7.4 & 4.2 & -3.2 \\
\hline & 1 & 1 & 0 & 1 & 0 & 1.1 & 3.4 & 2.3 & 4.2 & 8.2 & 4.0 \\
\hline & 1 & 1 & 0 & 1 & 1 & 1.8 & 6.3 & 4.5 & 12.5 & 25.1 & 12.6 \\
\hline & 1 & 1 & 1 & 0 & 0 & 0.7 & 0.4 & -0.3 & 0.3 & 0.2 & -0.1 \\
\hline & 1 & 1 & 1 & 0 & 1 & 1.5 & 0.5 & -1.0 & 1.7 & 0.6 & -1.1 \\
\hline & 1 & 1 & 1 & 1 & 0 & 2.5 & 3.2 & 0.7 & 0.6 & 1.4 & 0.8 \\
\hline Best outcome & 1 & 1 & 1 & 1 & 1 & 24.7 & 33.8 & 9.1 & 12.2 & 19.3 & 7.0 \\
\hline Sum & & & & & & 100 & 100 & 0 & 100 & 100 & 0 \\
\hline \multirow[t]{2}{*}{ Avg. number of good outcomes } & \multirow{2}{*}{\multicolumn{5}{|c|}{$\begin{array}{l}\text { Equal weights } \\
\text { Unequal weights }^{\text {b }}\end{array}$}} & 3.3 & 3.6 & 0.3 & 2.8 & 3.4 & 0.6 \\
\hline & & & & & & 3.0 & 3.4 & 0.4 & 3.2 & 3.8 & 0.6 \\
\hline
\end{tabular}

Source: see Table 1.

a Column headings $1,2,3,4,5$, refer to water, sanitation, shelter, communication, and education, respectively.

b Weighting scheme of $(2,2,1 / 3,1 / 3,1 / 3)$.

frequency that the column country is dominated by all other countries.

Most domination in both periods occurs when Gabon or South Africa dominate or when Burkina Faso, Chad, Ethiopia, Madagascar, or Mozambique are dominated. The remaining countries experience a greater occurrence of indeterminate outcomes. Indeterminate outcomes occur when two countries are either very similar or very different in the distribution of welfare in each indicator. Consistent with the principle of indivisibility and as noted in the discussion of Table 3, when welfare outcomes follow distinctly different patterns, FOD often cannot be determined. For example, in the second period Rwanda exhibits a particularly high degree of indeterminacy-it only dominates Ethiopia in bootstrap samples and is never dominated. This outcome likely stems from a unique pattern of relatively low water and shelter welfare coupled with the highest welfare in sanitation.

\subsubsection{Country rankings}

Table 7 presents country rankings in $t_{1}$ and $t_{2}$ based on the FOD and AF methodologies. In the static case, spatial FOD tests allow two countries to be ranked only when static results are determinate; however, bootstrap frequencies of net-domination enable a complete ranking of all countries (for a sufficient number of bootstrap repetitions). FOD net-domination measures the average frequency across all bootstrap samples that a country dominates all other countries minus the average frequency that it is dominated by all other countries (Tables 5 and 6 average bootstrap column values minus average bootstrap row values). To facilitate comparisons with the AF adjusted headcount ratio, $M_{0}$, we create the FOD domination score by linearly transforming FOD netdomination. Both the FOD domination score and $M_{0}$ have a range of $[0,1]$, where better rankings of multidimensional welfare correspond to lower values. ${ }^{7}$ As noted in Section 2.2, our AF poverty threshold $(k)$ identifies households with weighted deprivation shares of at least one-third as multidimensionally poor. In this study, indicators are assigned equal weight, and therefore, the poverty threshold corresponds to two deprivations.

Both methods identify the same sets of countries with the highest (South Africa, Gabon, Ghana, the Republic of Congo, and Senegal) and lowest (Mozambique, Madagascar, Chad, Ethiopia, Burkina Faso, and the DRC) multidimensional welfare rankings. FOD and AF also indicate large clusters of countries with similar outcomes. In $t_{2}$, half of all countries fall within a 10-point FOD domination score

\footnotetext{
7 Shading draws attention to clusters in which sequential countries do not outperform one another by more than two FOD domination points. In these cases, it is difficult to distinguish between differences in welfare and variability introduced through bootstrapping.
} 
Table 4

Temporal static FOD and normalized frequency of temporal bootstrap FOD.

\begin{tabular}{|c|c|c|c|c|}
\hline & $\begin{array}{l}\text { Time span } \\
\text { (years) }\end{array}$ & $\begin{array}{l}\text { Static } \\
\text { FOD }\end{array}$ & $\begin{array}{l}\text { Bootstrap } \\
\text { FOD } \\
\text { normalized } \\
\text { frequency }\end{array}$ & $\begin{array}{c}\text { Average } \\
\text { bootstrap } \\
\text { normalized } \\
\text { frequency }\end{array}$ \\
\hline Ethiopia & 11 & 1 & 1 & \multirow{26}{*}{0.92} \\
\hline Guinea & 7 & 1 & 1 & \\
\hline Kenya & 11 & 1 & 1 & \\
\hline Mali & 11 & 1 & 1 & \\
\hline Namibia & 13 & 1 & 1 & \\
\hline South Africa & 10 & 1 & 1 & \\
\hline Uganda & 11 & 1 & 1 & \\
\hline Zambia & 12 & 1 & 1 & \\
\hline Ghana & 11 & 1 & 0.99 & \\
\hline Malawi & 10 & 1 & 0.99 & \\
\hline Senegal & 7 & 1 & 0.99 & \\
\hline Benin & 10 & 1 & 0.93 & \\
\hline Lesotho & 10 & 1 & 0.91 & \\
\hline Chad & 10 & 1 & 0.82 & \\
\hline Mozambique & 8 & 1 & 0.57 & \\
\hline Zimbabwe & 5 & 1 & 0.48 & \\
\hline Cameroon & 7 & & 0.20 & \\
\hline Congo, D.R. & 12 & & 0.17 & \\
\hline Burkina Faso & 7 & & 0.14 & \\
\hline Madagascar & 4 & & 0.08 & \\
\hline Tanzania & 8 & & 0.06 & \\
\hline Congo, Rep. & 6 & & 0.04 & \\
\hline Côte d'Ivoire & 6 & & 0.03 & \\
\hline Rwanda & 14 & & 0.03 & \\
\hline Gabon & 12 & & 0 & \\
\hline Nigeria & 10 & & 0 & \\
\hline
\end{tabular}

Source: see Table 1.

range [0.44 and 0.54$]$ and a 14 -point $M_{0}$ range $[0.19,0.33]$. Despite the very different methodologies, the FOD domination score and $M_{0}$ have a correlation coefficient of 0.95 in both periods, and a Spearman rank correlation coefficient of 0.95 and 0.97 in $t_{1}$ and $t_{2}$, respectively. This high degree of correlation is consistent with applications by Arndt, Hussain, Salvucci, Tarp, and Østerdal (2016) to Mozambican census data, Arndt, Lerayo, Mahrt, and Tarp (2016) to Tanzanian DHS data, and Permanyer and Hussain (2017) to DHS data in 38 countries.
Changes in rankings over time must be interpreted carefully due to the large clusters of countries with very similar FOD domination scores and $M_{0}$. Nevertheless, a notable degree of rank persistence occurs, particularly with the AF methodology. Rankings change substantially between $t_{1}$ and $t_{2}$ in only a few countries. With the AF approach, only Lesotho moves more than a few ranks. Consistent with robust evidence of FOD temporal advancement, FOD domination scores indicate Lesotho, Guinea, and Zambia improve six, six, and five places, respectively. Tanzania, which 
Table 5

Normalized frequency of bootstrap spatial FOD, $t=t_{1}$.

\begin{tabular}{|c|c|c|c|c|c|c|c|c|c|c|c|c|c|c|c|c|c|c|c|c|c|c|c|c|c|c|c|}
\hline & ETH & TCD & MDG & $\mathrm{MOZ}$ & BFA & DRC & UGA & GIN & ZMB & BEN & MLI & NGA & MWI & KEN & LSO & TZA & NAM & ZWE & CMR & RWA & CIV & GHA & SEN & COG & GAB & ZAF & Avg \\
\hline ETH & & & & & & & & & & & & & & & & & & & & & & & & & & & 0 \\
\hline TCD & & & & & & & & & & & & & & & & & & & & & & & & & & & 0 \\
\hline MLI & 0.39 & & & & & & & & & & & & & & & & & & & & & & & & & & 0.02 \\
\hline DRC & 1 & & & & & & & & & & & & & & & & & & & & & & & & & & 0.04 \\
\hline MDG & 1 & $\underline{0.12}$ & & & & & & & & & & & & & & & & & & & & & & & & & 0.04 \\
\hline RWA & 1 & $\overline{0.35}$ & & & & & & & & & & & & & & & & & & & & & & & & & 0.05 \\
\hline BFA & 1 & $\overline{0.90}$ & & & & & & & & & & & & & & & & & & & & & & & & & 0.08 \\
\hline $\mathrm{MOZ}$ & 1 & 0.93 & & & & & & & & & & & & & & & & & & & & & & & & & 0.08 \\
\hline ZMB & 1 & 1 & & & & & & & & & & & & & & & & & & & & & & & & & 0.08 \\
\hline MWI & 1 & 1 & & & & & & & & & & & & & & & & & & & & & & & & & 0.08 \\
\hline ZWE & 1 & 1 & & & & & & & & & & & & & & & & & & & & & & & & & 0.08 \\
\hline LSO & 1 & 1 & $\underline{0.05}$ & & & & & & & & & & & & & & & & & & & & & & & & 0.08 \\
\hline UGA & 1 & 1 & & & & 0.10 & & & & & & & & & & & & & & & & & & & & & 0.08 \\
\hline KEN & 1 & 0.96 & & $\underline{0.02}$ & & $\overline{0.35}$ & & & & & & & & & & & & & & & & & & & & & 0.09 \\
\hline BEN & 1 & 0.97 & & & 0.71 & & & & & & & & & & & & & & & & & & & & & & 0.11 \\
\hline NAM & 1 & 1 & & & 0.79 & & & & & & & & & & & & & & & & & & & & & & 0.11 \\
\hline NGA & 1 & 0.93 & 0.99 & & & $\underline{0.01}$ & & & & & & & & & & & & & & & & & & & & & 0.12 \\
\hline GIN & 1 & 1 & 0.06 & 0.75 & 0.37 & & & & & & & & & & & & & & & & & & & & & & 0.13 \\
\hline TZA & 1 & 1 & & $\underline{0.04}$ & & 0.98 & $\underline{0.21}$ & & & & & & & & & & & & & & & & & & & & 0.13 \\
\hline CIV & 1 & 1 & 1 & 1 & 0.95 & & & $\underline{0.09}$ & & $\underline{0.01}$ & & & & & & & & & & & & & & & & & 0.20 \\
\hline GHA & 1 & 1 & 1 & 1 & 1 & & & 0.27 & & 0.01 & & & & & & & & & & & & & & & & & 0.21 \\
\hline CMR & 1 & 1 & 0.99 & 1 & 0.11 & 0.99 & 0.94 & & & & & & & & & & & & & & & & & & & & 0.24 \\
\hline SEN & 1 & 1 & 0.99 & 1 & $\overline{1}$ & & & 0.98 & & 0.61 & $\underline{0.28}$ & & & & & & & & & & & & & & & & 0.27 \\
\hline COG & 1 & 1 & 0.91 & 0.98 & & 1 & 0.48 & & 0.97 & & & & & & & 0.66 & & & & & & & & & & & 0.28 \\
\hline GAB & 1 & 1 & 1 & 1 & 1 & 1 & 1 & 1 & 1 & 0.77 & 1 & 1 & 1 & 0.67 & $\underline{0.24}$ & 0.51 & $\underline{0.01}$ & & 1 & 0.85 & $\underline{0.01}$ & & & & & & 0.64 \\
\hline ZAF & 1 & 1 & 1 & 1 & 1 & 1 & 0.79 & 1 & 1 & 1 & 1 & 1 & 0.99 & 1 & $\overline{1}$ & $\underline{0.04}$ & $\overline{1}$ & 1 & & & $\underline{0.21}$ & & & & & & 0.68 \\
\hline Avg. & 0.94 & 0.81 & 0.32 & 0.31 & 0.28 & 0.22 & 0.14 & 0.13 & 0.12 & 0.10 & 0.09 & 0.08 & 0.08 & 0.07 & 0.05 & $\overline{0.05}$ & 0.04 & 0.04 & 0.04 & 0.03 & 0.01 & 0 & 0 & 0 & 0 & 0 & 0.15 \\
\hline
\end{tabular}

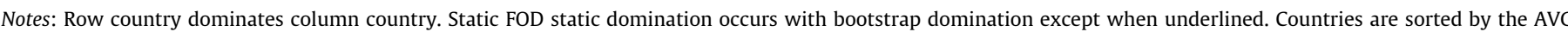
column (ascending) and row (descending). Country abbreviations are listed in Table 1.

Source: see Table 1.

Table 6

Normalized frequency of bootstrap spatial FOD, $t=t_{2}$.

\begin{tabular}{|c|c|c|c|c|c|c|c|c|c|c|c|c|c|c|c|c|c|c|c|c|c|c|c|c|c|c|c|}
\hline & ETH & TCDD & MOZ & MDG & BFA & BEN & DRC & NGA & ZMB & CIV & TZA & GIN & MLI & MWI & UGA & KEN & LSO & COG & CMR & SEN & NAM & ZWE & GAB & RWA & GHA & ZAF & Avg. \\
\hline ETH & & & & & & & & & & & & & & & & & & & & & & & & & & & 0 \\
\hline TCD & & & & & & & & & & & & & & & & & & & & & & & & & & & 0 \\
\hline MDG & & & & & & & & & & & & & & & & & & & & & & & & & & & 0 \\
\hline BFA & & & & & & & & & & & & & & & & & & & & & & & & & & & 0 \\
\hline DRC & $\underline{0.01}$ & & & & & & & & & & & & & & & & & & & & & & & & & & 0 \\
\hline MWI & $\overline{0.04}$ & $\underline{0.04}$ & & & & & & & & & & & & & & & & & & & & & & & & & 0 \\
\hline MOZ & $\underline{0.14}$ & & & & & & & & & & & & & & & & & & & & & & & & & & 0.01 \\
\hline RWA & 0.38 & & & & & & & & & & & & & & & & & & & & & & & & & & 0.02 \\
\hline MWI & 1 & & & & & & & & & & & & & & & & & & & & & & & & & & 0.04 \\
\hline BEN & & 1 & & & $\underline{0.24}$ & & & & & & & & & & & & & & & & & & & & & & 0.05 \\
\hline TZA & 1 & $\underline{0.12}$ & 0.59 & $\underline{0.01}$ & & & $\underline{0.21}$ & & & & & & & & & & & & & & & & & & & & 0.08 \\
\hline NAM & & $\overline{1}$ & & & 1 & & & & & & & & & & & & & & & & & & & & & & 0.08 \\
\hline UGA & 1 & 1 & $\underline{0.16}$ & & & & & & & & & & & & & & & & & & & & & & & & 0.09 \\
\hline GIN & 1 & 1 & $\overline{0.58}$ & 1 & $\underline{0.08}$ & & & & & & & & & & & & & & & & & & & & & & 0.15 \\
\hline KEN & 1 & 0.83 & 0.97 & 1 & & & & & & & $\underline{0.06}$ & & & & & & & & & & & & & & & & 0.15 \\
\hline ZWE & 1 & 0.96 & 1 & 1 & & & & & & & & & & & & & & & & & & & & & & & 0.16 \\
\hline NGA & 1 & 1 & 1 & 1 & & & & & & & & & & & & & & & & & & & & & & & 0.16 \\
\hline ZMB & 1 & 1 & 1 & 1 & & & & & & & & & & & & & & & & & & & & & & & 0.16 \\
\hline CMR & 1 & 1 & 1 & 1 & & & & & & & & & & & & & & & & & & & & & & & 0.16 \\
\hline LSO & 1 & 1 & 1 & 1 & 0.64 & 0.74 & & $\underline{0.06}$ & & & & & & & & & & & & & & & & & & & 0.22 \\
\hline CIV & 0.98 & 1 & 0.97 & 1 & 0.77 & 0.91 & & & & & & & & & & & & & & & & & & & & & 0.23 \\
\hline SEN & 1 & 1 & 1 & 1 & 0.71 & 0.94 & & & & & & $\underline{0.33}$ & & & & & & & & & & & & & & & 0.24 \\
\hline COG & 1 & 1 & 1 & 1 & $\underline{0.01}$ & & 0.99 & $\underline{0.04}$ & 1 & & 0.81 & $\underline{0.05}$ & & & & $\underline{0.01}$ & & & & & & & & & & & 0.28 \\
\hline GHA & 1 & 1 & 1 & 1 & 1 & 1 & & $\overline{0.97}$ & & 1 & & & & & & & & & & & & & & & & & 0.32 \\
\hline GAB & 1 & 1 & 1 & 1 & 1 & 1 & 1 & 1 & 1 & 0.91 & 0.97 & 1 & 0.99 & 0.96 & 0.81 & 0.45 & 0.36 & 0.26 & $\underline{0.11}$ & $\underline{0.01}$ & & & & & & & 0.63 \\
\hline ZAF & 1 & 1 & 1 & 1 & 1 & 1 & 1 & 1 & 1 & 1 & 1 & 1 & 1 & 1 & 1 & $\overline{1}$ & $\overline{1}$ & $\overline{1}$ & 0.99 & 1 & 1 & 1 & 0.67 & & & & 0.91 \\
\hline Avg. & 0.66 & 0.64 & 0.53 & 0.52 & 0.26 & 0.22 & 0.13 & 0.12 & 0.12 & 0.12 & 0.11 & 0.10 & 0.08 & 0.08 & 0.07 & 0.06 & 0.05 & 0.05 & 0.04 & 0.04 & 0.04 & 0.04 & 0.03 & 0 & 0 & 0 & 0.16 \\
\hline
\end{tabular}

Notes: see Table 5 . Source: see Table 1. 
Table 7

Country ranks by FOD domination scores and $M_{0}$.

\begin{tabular}{|c|c|c|c|c|c|c|c|c|c|c|}
\hline & \multicolumn{4}{|c|}{$t=t_{1}$} & \multicolumn{5}{|c|}{$t=t_{2}$} & \multirow{2}{*}{$\begin{array}{c}t_{2}=t_{1} \\
\text { Change }\end{array}$} \\
\hline & $\begin{array}{l}\text { FOD } \\
\text { dom. } \\
\text { score }\end{array}$ & Rank & $M_{0}$ & Rank & $\begin{array}{l}\text { FOD } \\
\text { dom. } \\
\text { score }\end{array}$ & Rank & Change & $M_{0}$ & Rank & \\
\hline South Africa** & 0.16 & 1 & 0.09 & 1 & 0.05 & 1 & 0 & 0.03 & 1 & 0 \\
\hline Gabon** & 0.18 & 2 & 0.12 & 2 & 0.20 & 2 & 0 & 0.05 & 2 & 0 \\
\hline Ghana* & 0.39 & 5 & 0.20 & 3 & 0.34 & 3 & -2 & 0.09 & 3 & 0 \\
\hline Congo, Rep.* & 0.36 & 3 & 0.23 & 4 & 0.39 & 4 & 1 & 0.14 & 4 & 0 \\
\hline Senegal & 0.36 & 4 & 0.26 & 7 & 0.40 & 5 & 1 & 0.16 & 5 & -2 \\
\hline Lesotho* & 0.48 & 12 & 0.30 & 10 & 0.42 & 6 & -6 & 0.17 & 6 & -4 \\
\hline Zimbabwe & 0.48 & 10 & 0.25 & 5 & 0.44 & 7 & -3 & 0.19 & 7 & 2 \\
\hline Cameroon* & 0.40 & 6 & 0.28 & 8 & 0.44 & 8 & 2 & 0.23 & 11 & 3 \\
\hline Côte d'Ivoire* & 0.40 & 7 & 0.25 & 6 & 0.45 & 9 & 2 & 0.20 & 8 & 2 \\
\hline Kenya* & 0.49 & 13 & 0.32 & 11 & 0.45 & 10 & -3 & 0.21 & 9 & -2 \\
\hline Guinea & 0.50 & 17 & 0.39 & 16 & 0.47 & 11 & -6 & 0.26 & 15 & -1 \\
\hline Namibia** & 0.46 & 9 & 0.33 & 12 & 0.48 & 12 & 3 & 0.21 & 10 & -2 \\
\hline Zambia* & 0.52 & 18 & 0.38 & 14 & 0.48 & 13 & -5 & 0.25 & 13 & -1 \\
\hline Nigeria* & 0.48 & 11 & 0.29 & 9 & 0.48 & 14 & 3 & 0.24 & 12 & 3 \\
\hline Rwanda & 0.49 & 14 & 0.49 & 19 & 0.49 & 15 & 1 & 0.36 & 20 & 1 \\
\hline Uganda & 0.53 & 19 & 0.40 & 17 & 0.49 & 16 & -3 & 0.26 & 14 & -3 \\
\hline Tanzania & 0.46 & 8 & 0.33 & 13 & 0.52 & 17 & 9 & 0.27 & 16 & 3 \\
\hline Malawi & 0.50 & 16 & 0.39 & 15 & 0.52 & 18 & 2 & 0.29 & 17 & 2 \\
\hline Mali & 0.54 & 20 & 0.49 & 20 & 0.54 & 19 & -1 & 0.33 & 19 & -1 \\
\hline Congo, D.R. & 0.59 & 21 & 0.52 & 22 & 0.56 & 20 & -1 & 0.40 & 21 & -1 \\
\hline Benin & 0.49 & 15 & 0.42 & 18 & 0.59 & 21 & 6 & 0.32 & 18 & 0 \\
\hline Burkina Faso & 0.60 & 22 & 0.52 & 21 & 0.63 & 22 & 0 & 0.43 & 22 & 1 \\
\hline Madagascar & 0.64 & 24 & 0.53 & 23 & 0.76 & 23 & -1 & 0.50 & 24 & 1 \\
\hline Mozambique & 0.62 & 23 & 0.54 & 24 & 0.76 & 24 & 1 & 0.46 & 23 & -1 \\
\hline Chad & 0.90 & 25 & 0.71 & 25 & 0.82 & 25 & 0 & 0.56 & 25 & 0 \\
\hline Ethiopia & 0.97 & 26 & 0.82 & 26 & 0.83 & 26 & 0 & 0.57 & 26 & 0 \\
\hline Average & 0.50 & 13.5 & 0.38 & 13.5 & 0.50 & 13.5 & 0 & 0.28 & 13.5 & 0 \\
\hline $\begin{array}{l}\text { FOD }-M_{0} \\
\text { correlation }\end{array}$ & 0.95 & & & & 0.95 & & & & & \\
\hline $\begin{array}{l}\text { Spearman rank } \\
\text { correlation }\end{array}$ & & 0.95 & & & & 0.97 & & & & \\
\hline
\end{tabular}

Notes: Sorted by $t_{2}$ FOD domination scores. Shaded areas highlight $t_{2}$ consecutive rankings based on very small differences in FOD domination scores. Care must be taken in interpretation due to variability introduced through bootstrapping.

Countries are low-income except: ${ }^{*}$ lower middle-income country; ${ }^{* *}$ upper middle-income country.

Source: see Table 1.

has no evidence of FOD temporal advancement, declines nine places. Despite a high likelihood of FOD temporal advancement, Benin falls from a rank of 15 to 21 . Though Benin advances in every indicator, its relative welfare, particularly in communication, advances more slowly than in Lesotho, Côte d'Ivoire, and Ghana, which results in more cases of Benin being dominated. This example and the somewhat greater degree of rank fluctuation with the FOD methodology in general likely stems from FOD's strict consideration of the full welfare distribution. Comparisons of FOD and AF outcomes are discussed in more detail in the next section.

\subsubsection{FOD versus $A F$}

This section highlights how FOD's strict adherence to the principles of inalienability and equality results in divergent FOD and AF rankings. South Africa ranks highest in both time periods using both methodologies. However, FOD indicates that South Africa dominates other countries with greater frequency in $t_{2}$ compared to $t_{1}$. This more frequent dominance by South Africa compares to a convergence (catch-up by other countries) that occurs in AF. This difference highlights a fundamental distinction between the AF and FOD approaches, which is that FOD requires domination in 
all dimensions. It also recalls the discussion at the end of Section 2.4, which emphasizes the ordinal nature of FOD and the property of the net-domination measure as a frequency count. South Africa dominated other nations less frequently in $t_{1}$. For example, in $t_{1}$, all bootstrap comparisons between South Africa and Gabon are indeterminate even though South Africa outperformed Gabon in terms of the share of the population not deprived in all dimensions except sanitation (Table 5). Relative welfare gains in South African sanitation result in South Africa dominating Gabon in 67 bootstrap comparisons in $t_{2}$ (Table 6). Similar scenarios occur between South Africa and other top-performing countries, including the Republic of Congo, Senegal, and Cameroon. Consequently, the FOD domination score captures more frequent domination of other countries by South Africa in $t_{2}$. In contrast, $\mathrm{AF}$ indicates an overall catching up by other countries in terms of average incidence and intensity of deprivations as captured by the MPI.

A similar difference between FOD and AF exists when comparing temporal outcomes. In contrast to temporal FOD (Table 4), the AF method indicates progress in every country in terms of reduced $M_{0}$. Greater reductions in $M_{0}$ generally correspond to higher frequencies of FOD improvement. Notable differences include Rwanda and the DRC, which reduce $M_{0}$ by 0.13 and 0.14 without FOD advancement, while South Africa improves $M_{0}$ by only 0.05 but achieves FOD advancement in every bootstrap iteration. The finding of stagnation in 10 countries using FOD and progress in all countries using AF stems from $M_{0}$ 's derivation from average poverty incidence and intensity levels compared to FOD's strict criteria that advancement must occur in all indicators and throughout the distribution. The methods are complementary in that $M_{0}$ provides a sense of overall trends while FOD, in a sense, establishes a lower bound consistent with the basic human rights framework. Temporal FOD is difficult to achieve, but when it occurs it robustly indicates progress without neglecting any welfare dimensions or any segment of the population. While FOD is more consistent with the principles of basic human rights, both measures provide useful information regarding relative welfare and welfare advancement.

\subsubsection{Middle-income countries}

The asterisks in Table 7 indicate upper (double asterisk) and lower middle-income (single asterisk) country status. ${ }^{8}$ A strong correspondence exists between middle-income status and FOD and $M_{0}$ rankings in both time periods. Senegal and Zimbabwe are exceptions; they are not middle-income countries but outperform some middle-income countries in both time periods. In $t_{1}$, Zambia had not yet achieved middle-income status and had a relatively poor FOD rank of 18 among the 26 countries studied here. Though it exhibits a strong likelihood of rank advancement between periods, Zambia remained at the bottom of the middle-income countries in $t_{2}$. Nigeria (Africa's most populous nation) does not exhibit progress in the temporal analysis. Moreover, it ranks poorly among middleincome countries in $t_{2}$. This weak performance can be attributed to relatively low welfare in water and sanitation, backsliding in sanitation and flooring, and stagnation in education. Nigeria has not been able to approach the other major oil exporters, Cameroon and Gabon (see also Collier, Soludo, and Pattillo (2008) on Nigeria's performance and challenges).

\subsubsection{Correlations with other welfare measures}

Table 8 presents several common measures of wellbeing and their associated rankings for the 26 study countries. These

\footnotetext{
${ }^{8}$ Lower middle-income economies are those with a per capita PPP adjusted gross national income (GNI) between US\$1026 and US\$4035, and upper middle-income economies are those with a per capita PPP adjusted GNI between US\$4036 and US $\$ 12,475$ (World Bank, 2016a).
}

measures include the World Bank's US\$1.90 and US\$3 per day poverty headcount ratios, gross domestic product (GDP), average annual GDP per capita growth, UNDP's Human Development Index (HDI), and UNDP's MPI, which measures $M_{0}$ for an internationally standardized set of indicators. Excluding GDP growth, the rankings suggest that for a given country this collection of indicators might tell very similar (Gabon, Ghana, Mozambique, and South Africa) or very different stories (Chad, Ethiopia, and Madagascar).

Table 9 presents correlation and Spearman rank correlation coefficients between the FOD domination score and each welfare measure. The FOD domination score is most highly correlated with the other measure of multidimensional welfare, the MPI (0.82), and the HDI ( -0.72$)$, and to a lesser degree with GDP per capita $(-0.67)$ and the US\$3.20 per day poverty headcount ratio (0.66). FOD is only moderately correlated with the often-cited US $\$ 1.90$ poverty headcount ratio (0.53), which reiterates the need for triangulation in poverty analysis.

These results are consistent with findings of two recent crosscountry studies of multidimensional poverty in SSA. Batana (2013) finds low and positive Spearman rank correlations between $M_{0}$ and both monetary and asset poverty headcounts, and negative and moderate to high correlations between $M_{0}$ and HDI. Alkire and Housseini (2014) consider the relationship between multidimensional poverty and monetary poverty dynamics. Their analysis finds that, among the countries with two periods of consistent MPI ratios and US\$1.25 per day poverty ratios, half the countries reduced multidimensional poverty faster than income poverty. They also found a low correlation between annualized reductions in $M_{0}$ and annualized growth in GNI.

\subsubsection{Indicator sensitivity analysis}

Greater detail in recent DHS questionnaires allows us to specify improved water and sanitation indicators in $t_{2}$ following United Nations Children's Fund and World Health Organization (2015) thresholds and to evaluate sensitivity to indicator thresholds. ${ }^{9}$ The default water indicator classifies tap, pipe, public standpipe, tube-well, borehole, covered dug well, rainwater, or bottled/sachet water as non-deprived sources. The improved water indicator also includes protected springs as non-deprived. The default sanitation indicator classifies households using any sanitation facility as nondeprived. The improved sanitation facilities indicator excludes pit latrines without a slab and facilities that flush or pour to somewhere other than a sewer system, septic tank, or pit latrine. We define improved sanitation with and without the criterion that improved sanitation is not shared.

Table 10 presents average welfare levels based on original water and sanitation indicators and improved water and sanitation indicators (with and without the shared sanitation criterion). In most of the countries, using the improved water indicator results in virtually no change in terms of the share of population classified as not deprived in this indicator. However, in Cameroon, the DRC, Ethiopia, Kenya, and Rwanda, increased welfare is significant at $6,17,9,10$, and 32 percentage points, respectively. Thus, the population-weighted aggregate welfare increases from 58.4 per cent using the original water indicator to 62.9 per cent with the improved water indicator. In contrast, welfare in sanitation is profoundly different both in terms of levels and relative welfare between the countries. Modifications to the sanitation indicator significantly decrease aggregate sanitation welfare from 73.9 per cent to 40.7 per cent and 23.9 per cent using the improved and unshared improved sanitation indicators, respectively.

\footnotetext{
${ }^{9}$ The 2012 South Africa GHS does not distinguish between covered and uncovered pit latrines and therefore South Africa was excluded from the sensitivity analysis.
} 
Table 8

Common welfare measures (2012 except where noted).

\begin{tabular}{|c|c|c|c|c|c|c|c|c|c|c|c|c|}
\hline & \multicolumn{2}{|c|}{$\begin{array}{l}\text { US\$1.90 } \\
\text { poverty rate }\end{array}$} & \multicolumn{2}{|c|}{$\begin{array}{l}\text { US } \$ 3.20 \\
\text { poverty rate }\end{array}$} & \multicolumn{2}{|l|}{ GDP per capita } & \multicolumn{2}{|c|}{$\begin{array}{l}\text { GDP per } \\
\text { capita } \\
\text { growth }^{\mathrm{b}}\end{array}$} & \multicolumn{2}{|l|}{ HDI } & \multicolumn{2}{|l|}{$\mathrm{MPI}^{\mathrm{a}}$} \\
\hline & $(\%)$ & Rank & $(\%)$ & Rank & Constant 2010 US\$ & Rank & $(\%)$ & $(\%)$ & Index & Rank & Index & Rank \\
\hline Benin & 53.1 & 18 & 75.6 & 16 & 747 & 17 & 0.6 & 21 & 0.48 & 16 & 0.31 & 14 \\
\hline Burkina Faso & 43.7 & 15 & 74.7 & 15 & 614 & 20 & 3.1 & 13 & 0.39 & 25 & 0.54 & 24 \\
\hline Cameroon & 24.0 & 5 & 43.5 & 3 & 1188 & 9 & 0.8 & 20 & 0.50 & 11 & 0.25 & 9 \\
\hline Chad & 38.4 & 14 & 64.8 & 10 & 913 & 13 & 6.0 & 2 & 0.39 & 26 & 0.55 & 25 \\
\hline Congo, D.R. & 77.1 & 25 & 90.7 & 26 & 334 & 26 & 2.4 & 15 & 0.42 & 21 & 0.40 & 21 \\
\hline Congo, Rep. & 37.0 & 12 & 59.6 & 9 & 3007 & 4 & 1.8 & 18 & 0.58 & 5 & 0.18 & 6 \\
\hline Côte d'Ivoire & 29.0 & 7 & 55.1 & 7 & 1248 & 8 & -0.5 & 24 & 0.45 & 18 & 0.31 & 16 \\
\hline Ethiopia & 33.5 & 8 & 71.3 & 14 & 392 & 25 & 6.1 & 1 & 0.43 & 20 & 0.56 & 26 \\
\hline Gabon & 8.0 & 1 & 24.4 & 1 & 10,031 & 1 & 0.0 & 23 & 0.67 & 1 & 0.07 & 2 \\
\hline Ghana & 25.2 & 6 & 49.0 & 6 & 1570 & 6 & 4.3 & 8 & 0.57 & 6 & 0.16 & 5 \\
\hline Guinea & 35.3 & 11 & 68.7 & 13 & 440 & 23 & 0.4 & 22 & 0.41 & 23 & 0.46 & 23 \\
\hline Kenya & 33.6 & 9 & 58.9 & 8 & 1043 & 11 & 1.9 & 17 & 0.54 & 7 & 0.19 & 7 \\
\hline Lesotho & 59.7 & 20 & 77.3 & 19 & 1162 & 10 & 3.2 & 12 & 0.48 & 13 & 0.16 & 4 \\
\hline Madagascar & 77.8 & 26 & 90.5 & 25 & 409 & 24 & -0.5 & 25 & 0.51 & 9 & 0.36 & 18 \\
\hline Malawi & 70.9 & 24 & 87.6 & 24 & 474 & 21 & 2.5 & 14 & 0.43 & 19 & 0.27 & 11 \\
\hline Mali & 49.3 & 17 & 77.7 & 20 & 794 & 15 & 5.4 & 4 & 0.41 & 22 & 0.46 & 22 \\
\hline Mozambique & 68.7 & 23 & 87.5 & 23 & 453 & 22 & 4.5 & 6 & 0.41 & 24 & 0.39 & 20 \\
\hline Namibia & 22.6 & 4 & 45.7 & 5 & 5436 & 3 & 3.5 & 10 & 0.62 & 3 & 0.19 & 8 \\
\hline Nigeria & 53.5 & 19 & 76.5 & 18 & 2399 & 5 & 6.0 & 3 & 0.51 & 10 & 0.30 & 13 \\
\hline Rwanda & 60.4 & 21 & 80.7 & 22 & 618 & 19 & 5.4 & 5 & 0.48 & 14 & 0.26 & 10 \\
\hline Senegal & 38.0 & 13 & 66.3 & 12 & 997 & 12 & 1.0 & 19 & 0.46 & 17 & 0.31 & 15 \\
\hline South Africa & 16.6 & 2 & 34.7 & 2 & 7564 & 2 & 2.0 & 16 & 0.66 & 2 & 0.04 & 1 \\
\hline Tanzania & 46.6 & 16 & 76.1 & 17 & 754 & 16 & 3.5 & 11 & 0.51 & 8 & 0.33 & 17 \\
\hline Uganda & 34.6 & 10 & 65.0 & 11 & 653 & 18 & 4.0 & 9 & 0.48 & 15 & 0.37 & 19 \\
\hline Zambia & 64.4 & 22 & 78.9 & 21 & 1557 & 7 & 4.5 & 7 & 0.58 & 4 & 0.28 & 12 \\
\hline Zimbabwe & 21.4 & 3 & 45.5 & 4 & 800 & 14 & -3.4 & 26 & 0.49 & 12 & 0.13 & 3 \\
\hline
\end{tabular}

Source: United Nations Development Programme (2016a), World Bank (2016b), and own calculations.

a Most recent survey.

b Average annual growth over the period 2002-12.

Table 9

Correlations between FOD and common welfare measures in survey closest to 2012 (Spearman rank correlations in parentheses).

\begin{tabular}{|c|c|c|c|c|c|c|c|}
\hline & FOD & US\$1.90 & US\$3.20 & GDP per capita & HDI & & MPI \\
\hline FOD & 1 & & & & & & \\
\hline US $\$ 1.90$ & $0.53(0.59)$ & 1 & & & & & \\
\hline US\$3.20 & $0.66(0.65)$ & $0.94(0.97)$ & 1 & & & & \\
\hline GDP per capita & $-0.67(-0.75)$ & $-0.58(-0.56)$ & $-0.73(-0.67)$ & 1 & & & \\
\hline HDI & $-0.72(-0.65)$ & $-0.48(-0.39)$ & $-0.66(-0.44)$ & $0.81(0.72)$ & 1 & & \\
\hline MPI & $0.82(0.82)$ & $0.37(0.41)$ & $-0.59(-0.49)$ & $-0.61(-0.71)$ & -0.82 & $(-0.80)$ & 1 \\
\hline
\end{tabular}

Source: see Tables 1 and 7.

Table 11 presents FOD and $M_{0}$ rankings using improved indicators. Despite differences in welfare levels, spatial comparisons are not vastly different and result in no major changes in the top or bottom tiers. Most countries falling in the middle move no more than a few ranks, which is not a robust result given the tight clusters of domination scores and variability introduced with bootstrapping. There are a few exceptions. Most notably, with both sets of improved indicators, Benin and Namibia perform significantly better using the FOD and AF methodologies and Rwanda performs better using the AF methodology, bringing it closer in line with spatial FOD rankings for $t_{2}$. Accounting for sensitivity to methodology and indicator choice, it would be reasonable to draw general conclusions regarding the relative welfare of countries, such as: 'Senegal falls in the upper quarter'; 'Malawi falls in the lower middle'; and 'Gabon dominates most countries'. However, caution is pertinent in comparisons among tightly clustered countries. For example, 'Nigeria outperforms Rwanda' is a claim that does not hold across indicator choice and which is not robust to differences in FOD dominance scores.

\section{Conclusion}

In this study, the FOD and AF approaches to evaluating multidimensional welfare were presented and applied to 26 SSA countries in two-time periods. Primary data came from the DHS, except for the South African national household surveys and the 2001 DRC MICS. Surveys from years as close to 2002 and 2012 as possible were applied for each of the 26 included countries. Using both methodologies, we evaluated whether a country has achieved welfare gains between two-time periods and whether one country dominates another.

While FOD conforms well to three fundamental principles of human rights, AF does not. First, FOD comparisons are independent of any applied weighting schemes (indivisibility). Second, FOD cannot be established when welfare in any indicator is deteriorating, no matter how great the advancement is in other indicators (inalienability). Finally, FOD requires that domination occurs throughout the population (equality). Welfare gains among better-off groups never offset welfare losses among worse-off 
Table 10

Individuals not deprived in default and improved water and sanitation indicators, $t=t_{2}$ (per cent).

\begin{tabular}{|c|c|c|c|c|c|}
\hline & Default water & Improved water & Default sanitation & Improved sanitation & Improved sanitation (not shared) \\
\hline Benin & 75 & 77 & 41 & 31 & 15 \\
\hline Burkina Faso & 76 & 77 & 36 & 30 & 16 \\
\hline Cameroon & 63 & 69 & 92 & 57 & 40 \\
\hline Chad & 56 & 56 & 30 & 15 & 8 \\
\hline Congo, D.R. & 34 & 51 & 87 & 41 & 21 \\
\hline Congo, Rep. & 73 & 77 & 90 & 43 & 14 \\
\hline Côte d'Ivoire & 78 & 78 & 66 & 47 & 22 \\
\hline Ethiopia & 42 & 51 & 62 & 16 & 9 \\
\hline Gabon & 89 & 93 & 91 & 63 & 38 \\
\hline Ghana & 88 & 88 & 79 & 70 & 15 \\
\hline Guinea & 75 & 76 & 83 & 45 & 21 \\
\hline Kenya & 57 & 67 & 87 & 48 & 25 \\
\hline Lesotho & 77 & 82 & 71 & 70 & 51 \\
\hline Madagascar & 37 & 40 & 56 & 6 & 3 \\
\hline Malawi & 79 & 79 & 90 & 14 & 9 \\
\hline Mali & 66 & 66 & 88 & 42 & 24 \\
\hline Mozambique & 53 & 53 & 61 & 28 & 24 \\
\hline Namibia & 84 & 84 & 49 & 45 & 34 \\
\hline Nigeria & 63 & 64 & 70 & 54 & 34 \\
\hline Rwanda & 40 & 72 & 97 & 72 & 58 \\
\hline Senegal & 78 & 78 & 82 & 63 & 49 \\
\hline Tanzania & 54 & 56 & 86 & 34 & 24 \\
\hline Uganda & 70 & 70 & 90 & 32 & 19 \\
\hline Zambia & 63 & 64 & 84 & 45 & 28 \\
\hline Zimbabwe & 76 & 77 & 71 & 62 & 38 \\
\hline
\end{tabular}

Source: see Table 1.

Table 11

Country ranks by FOD domination scores and $M_{0}$ using the improved water and sanitation indicators $\left(t=t_{2}\right)$.

\begin{tabular}{|c|c|c|c|c|c|c|c|c|}
\hline & \multicolumn{4}{|c|}{$\begin{array}{l}\text { No distinction between shared and unshared sanitation } \\
\text { facilities }\end{array}$} & \multicolumn{4}{|c|}{ Shared sanitation facilities are a deprivation } \\
\hline & FOD dom. score & Rank & $M_{0}$ & Rank & FOD dom. score & Rank & $M_{0}$ & Rank \\
\hline Gabon & 0.16 & 1 & 0.09 & 1 & 0.17 & 1 & 0.10 & 1 \\
\hline Ghana & 0.21 & 3 & 0.10 & 2 & 0.41 & 6 & 0.14 & 2 \\
\hline Congo, Rep. & 0.38 & 7 & 0.21 & 6 & 0.44 & 9 & 0.23 & 4 \\
\hline Senegal & 0.35 & 5 & 0.21 & 4 & 0.35 & 4 & 0.23 & 6 \\
\hline Lesotho & 0.20 & 2 & 0.16 & 3 & 0.20 & 2 & 0.17 & 3 \\
\hline Zimbabwe & 0.40 & 8 & 0.21 & 5 & 0.40 & 5 & 0.23 & 7 \\
\hline Cameroon & 0.48 & 13 & 0.30 & 11 & 0.44 & 9 & 0.32 & 11 \\
\hline Côte d'Ivoire & 0.41 & 9 & 0.24 & 8 & 0.41 & 7 & 0.28 & 8 \\
\hline Kenya & 0.37 & 6 & 0.28 & 10 & 0.43 & 8 & 0.31 & 10 \\
\hline Guinea & 0.53 & 15 & 0.35 & 15 & 0.52 & 15 & 0.38 & 15 \\
\hline Namibia & 0.27 & 4 & 0.21 & 7 & 0.24 & 3 & 0.23 & 5 \\
\hline Zambia & 0.46 & 10 & 0.33 & 12 & 0.46 & 13 & 0.35 & 12 \\
\hline Nigeria & 0.48 & 12 & 0.28 & 9 & 0.46 & 11 & 0.30 & 9 \\
\hline Rwanda & 0.46 & 11 & 0.34 & 13 & 0.46 & 11 & 0.36 & 14 \\
\hline Uganda & 0.54 & 16 & 0.40 & 17 & 0.52 & 16 & 0.42 & 17 \\
\hline Tanzania & 0.55 & 17 & 0.39 & 16 & 0.53 & 17 & 0.40 & 16 \\
\hline Malawi & 0.58 & 18 & 0.47 & 21 & 0.57 & 18 & 0.48 & 20 \\
\hline Mali & 0.61 & 19 & 0.44 & 18 & 0.58 & 19 & 0.47 & 19 \\
\hline Congo, D.R. & 0.65 & 21 & 0.46 & 20 & 0.64 & 21 & 0.49 & 21 \\
\hline Benin & 0.50 & 14 & 0.34 & 14 & 0.51 & 14 & 0.36 & 13 \\
\hline Burkina Faso & 0.63 & 20 & 0.44 & 19 & 0.60 & 20 & 0.47 & 18 \\
\hline Madagascar & 0.79 & 23 & 0.59 & 23 & 0.79 & 23 & 0.60 & 23 \\
\hline Mozambique & 0.79 & 22 & 0.53 & 22 & 0.66 & 22 & 0.54 & 22 \\
\hline Chad & 0.84 & 24 & 0.60 & 24 & 0.84 & 24 & 0.61 & 24 \\
\hline Ethiopia & 0.88 & 25 & 0.65 & 25 & 0.89 & 25 & 0.66 & 25 \\
\hline Average & 0.50 & 13 & 0.34 & 13 & 0.50 & 13 & 0.36 & 13 \\
\hline FOD $-M_{0}$ correlation & 0.98 & & & & 0.95 & & & \\
\hline Spearman rank correlation & & 0.97 & & & & 0.97 & & \\
\hline
\end{tabular}

Source: see Table 1 .

groups. In contrast, the AF approach relies on weighting schemes and makes use of average outcomes to compile a welfare index, and therefore goes against the principles of indivisibility, inalienability, and equality. The strength of the AF approach is that it is useful in summarizing welfare trends and provides an indication of multidimensional welfare when FOD results are indeterminate.
In all analyses, we find that South Africa and/or Gabon top the country rankings. Other top performers include Ghana, the Republic of Congo, Senegal, and in some cases Zimbabwe and Lesotho. Ethiopia, Chad, Mozambique, Madagascar, Burkina Faso, and the DRC are consistently in the bottom tier. Great strides in access to basic amenities in Ethiopia and Chad have led to less 
differentiation among the bottom ranks. The remaining countries are tightly clustered in the middle and often difficult to rank with confidence. Middle-income countries outperform lower-income countries in most cases.

For the 26 SSA nations, neither AF nor FOD indicate regress, but the methodologies diverge on their assessment of progress over the study period. While the AF methodology suggests that all countries are advancing on average, the FOD, with its strict adherence to criteria that are consistent with human rights, is less categorical. FOD indicates that 14 countries experienced broad-based increases in welfare, while two countries show more moderate likelihoods of progress, and the remaining 10 countries neither improve nor deteriorate in terms of multidimensional welfare. In sum, for SSA as a region, we can safely conclude that welfare is improving. At the same time, challenges remain in assuring that benefits of well-documented growth are widely distributed.

\section{Acknowledgments}

The authors are grateful to two anonymous referees for helpful comments. The usual caveats apply.

\section{References}

Ajakaiye, O., Jerome, A. T., Olaniyan, O., Mahrt, K., \& Alaba, O. (2016). Measuring Multidimensional Poverty in Nigeria. In C. Arndt \& F. Tarp (Eds.), Measuring Poverty and Wellbeing in Developing Countries. Oxford: Oxford University Press.

Alkire, S., \& Foster, J. (2007). Counting and multidimensional poverty measurement OPHI Working Paper 7. Oxford: Oxford Poverty and Human Development Initiative, University of Oxford.

Alkire, S., Foster, J., Seth, S., Santos, M. E. Roche, J. M. \& Ballon, P. (2015). Multidimensional poverty measurement and analysis. Oxford: Oxford University Press. 10.1093/acprof:oso/9780199689491.001.0001.

Alkire, S., \& Housseini, B. (2014). Multidimensional poverty in Sub-Saharan Africa: Levels and trends OPHI Working Paper 81. Oxford: Oxford Poverty and Human Development Initiative, University of Oxford.

Alkire, S., \& Santos, M. E. (2010). Acute multidimensional poverty: A new index for developing countries OPHI Working Paper 38. Oxford: Oxford Poverty and Human Development Initiative, University of Oxford.

Arndt, C., Distante, R., Hussain, M. A., Østerdal, L. P., Huong, P. L., \& Ibraimo, M. (2012). Ordinal welfare comparisons with multiple discrete indicators: A first order dominance approach and application to child poverty. World Development, 40, 2290-2301. https://doi.org/10.1016/j.worlddev.2012.03.010.

Arndt, C., Hussain, M. A., Salvucci, V., Tarp, F., \& Østerdal, L. P. (2016). Poverty mapping based on first-order dominance with an example from Mozambique. Journal of International Development, 28, 3-21. https://doi.org/10.1002/jid.3200.

Arndt, C., Lerayo, V., Mahrt, K., \& Tarp, F. (2016). Multidimensional Assessment of Child Welfare in Tanzania. In C. Arndt \& F. Tarp (Eds.), Measuring poverty and wellbeing in developing countries. Oxford: Oxford University Press.

Arndt, C., \& Mahrt, K. (2016). Estimation in Practice. In C. Arndt \& F. Tarp (Eds.) Measuring poverty and wellbeing in developing countries. Oxford: Oxford University Press.

Arndt, C., McKay, A., \& Tarp, F. (Eds.). (2016). Growth and poverty in Sub-Saharan Africa. Oxford: Oxford University Press.

Arndt, C., Østerdal, L. P., \& Siersbæk, N. (2016). Multidimensional first-orde dominance comparisons of population wellbeing. In C. Arndt \& F. Tarp (Eds.) Measuring poverty and wellbeing in developing countries. Oxford: Oxford University Press.

Arndt, C., \& Tarp, F. (Eds.). (2016). Measuring poverty and wellbeing in developing countries. Oxford: Oxford University Press.

Atkinson, A., \& Bourguignon, F. (1982). The comparison of multi-dimensioned distributions of economic status. The Review of Economic Studies, 49, 183-201. https://doi.org/10.2307/2297269.

Batana, Y. (2013). Multidimensional measurement of poverty among women in Sub-Saharan Africa. Social Indicators Research, 112, 337-362. https://doi.org 10.1007/s11205-013-0251-9.

Bérenger, V., Bresson, F., Makdissi, P., \& Yazbeck, M. (2013). Regional and sectora distributions of poverty in Lebanon, 2004. In V. Bérenger \& F. Bresson (Eds.), Economic studies in inequality, social exclusion and well-being: Volume 9. Poverty and social exclusion around the mediterranean sea. New York: Springer.

Booysen, F., Van Der Berg, S., Burger, R., Von Maltitz, M., \& Du Rand, G. (2008). Using an asset index to assess trends in poverty in Seven Sub-Saharan African Countries. World Development, 36, 1113-1130. https://doi.org/10.1016/ j.worlddev.2007.10.008.

Bourguignon, F. (2004). The poverty-growth-inequality triangle Working Paper 125 New Delhi: Indian Council for Research on International Economic Relations.

Bourguignon, F., \& Chakravarty, S. (2003). The measurement of multidimensional poverty. Journal of Economic Inequality, 1, 25-49. https://doi.org/10.1023/ A: 1023913831342
Collier, P., Soludo, C. C., \& Pattillo, C. (Eds.). (2008). Economic policy options for a prosperous Nigeria. Basingstoke: Palgrave Macmillan.

Copeland, A.H. (1951). 'A “Reasonable” Social Welfare Function'. In Seminar on Application of Mathematics to the Social Sciences. University of Michigan: Mimeo.

Cowell, F. A., \& Victoria-Feser, M.-P. (2007). Robust stochastic dominance: A semiparametric approach. Journal of Economic Inequality, 5, 21-37. https://doi.org/ $10.1007 / \mathrm{s} 10888-006-9022-\mathrm{z}$

DHS (2016). 'DHS Overview’. http://www.measuredhs.com/What-We-Do/SurveyTypes/DHS.cfm (accessed July 29, 2016).

Duclos, J. Y., \& Échevin, D. (2011). Health and income: A robust comparison of Canada and the US. Journal of Health Economics, 30, 293-302. https://doi.org/ 10.1016/j.jhealeco.2010.12.002.

Duclos, J. Y., \& Makdissi, P. (2005). Sequential stochastic dominance and the robustness of poverty orderings. Review of Income and Wealth, 51, 63-87. https://doi.org/10.1111/j.1475-4991.2005.00145.x.

Duclos, J. Y., Sahn, D., \& Younger, S. (2007). Robust multidimensional poverty comparisons with discrete indicators of well-being. In S. P. Jenkins \& J. Micklewright (Eds.), Inequality and poverty reexamined. Oxford: Oxford University Press.

Duclos, J. Y., Sahn, D., \& Younger, S. (2011). Partial multidimensional inequality orderings. Journal of Public Economics, 95, 225-238. https://doi.org/10.1016/j. jpubeco.2010.10.015.

Dyckerhoff, R., \& Mosler, K. (1997). Orthant orderings of discrete random vectors. Journal of Statistical Planning and Inference, 62, 193-205. https://doi.org/ 10.1016/S0378-3758(96)00184-X.

Efron, B. (1979). Bootstrap methods: Another look at the Jackknife. Annals of Statistics, 7, 1-26. https://doi.org/10.1214/aos/1176344552.

Foster, J., Greer, J., \& Thorbecke, E. (1984). A class of decomposable poverty measures. Econometrica, 52(3), 761-766. https://doi.org/10.2307/1913475.

Fosu, A. K. (2015). Growth, inequality and poverty in Sub-Saharan Africa: Recent progress in a global context. Oxford Development Studies, 43(1), 44-59. https:/| doi.org/10.1080/13600818.2014.964195.

Gordon, F., Nandy, F., Pantazis, C., Pemberton, S., \& Townsend, P. (2003). Child poverty in the developing world. Bristol: Policy Press.

Gravel, N., \& Moyes, P. (2012). Ethically robust comparisons of bidimensional distributions with an ordinal attribute. Journal of Economic Theory, 147(4), 1384-1426. https://doi.org/10.1016/j.jet.2012.01.001.

Gravel, N., Moyes, P., \& Tarroux, B. (2009). Robust international comparisons of distributions of disposable income and regional public goods. Economica, 76, 432-461. https://doi.org/10.1111/j.1468-0335.2008.00688.x.

Gravel, N., \& Mukhopadhyay, A. (2010). Is India better off today than 15 years ago? A robust multidimensional answer. The Journal of Economic Inequality, 8, 173-195. https://doi.org/10.1007/s10888-009-9112-9.

IMF (2013). World Economic Outlook Database. October 2013. https://www.imf. org/external/pubs/ft/weo/2017/01/weodata/index.aspx (accessed August 4, 2017).

Lehmann, E. (1955). Ordered families of distributions. The Annals of Mathematical Statistics, 26, 399-419.

Levhari, D., Paroush, J., \& Peleg, B. (1975). Efficiency analysis for multivariate distributions. Review of Economic Studies, 42, 87-91. https://doi.org/10.2307/ 2296822.

Mahrt, K., \& Masumbu, G. (2016). Estimating multidimensional poverty in Zambia. In C. Arndt \& F. Tarp (Eds.), Measuring poverty and wellbeing in developing countries. Oxford: Oxford University Press.

Mosler, K., \& Scarsini, M. (1991). Some theory of stochastic dominance. In K. Mosler \& M. Scarsini (Eds.), Stochastic orders and decision under risk. Heyward, CA: Institute of Mathematical Statistics.

Østerdal, L. P. (2010). The mass transfer approach to multivariate discrete first order stochastic dominance: Direct proof and implications. Journal of Mathematical Economics, 46(6), 1222-1228. https://doi.org/10.1016/j.jmateco.2010.08.018.

Permanyer, I., \& Hussain, M. A. (2017). First order dominance techniques and multidimensional poverty indices: An empirical comparison of different approaches. Social Indicators Research. https://doi.org/10.1007/s11205-0171637-x.

Ravallion, M. (2016). The economics of poverty: History, measurement, and policy. Oxford: Oxford University Press.

[dataset]RDdC (2002). Enquête Nationale sur la Situation des Enfants et des Femmes MICS2/2001. Kinshasa: République Démocratique du Congo, UNICEF, and USAID.

Sahn, D., \& Stifel, D. (2000). Poverty comparisons over time and across countries in Africa. World Development, 28, 2123-2155. https://doi.org/10.1016/S0305-750X (00)00075-9.

Shaked, M., \& Shanthikumar, G. (2007). Stochastic orders. New York: SpringerVerlag.

Statistics South Africa (2003). General household survey July 2002. Statistical release P0318. Pretoria: Statistics South Africa.

Statistics South Africa (2013). General household survey 2012. Statistical release P0318 Revised October 4, 2013. Pretoria: Statistics South Africa.

Thorbecke, E. (2013). The interrelationship linking growth, inequality and poverty in Sub-Saharan Africa. Journal of African Economies, 22(Suppl_1), i15-i48. https://doi.org/10.1093/jae/ejs028.

United Nations (2015). The Millennium Development Goals Report: 2015. New York: United Nations.

United Nations Children's Fund (2004). State of the world's children. New York: United Nations Children's Fund. 
United Nations Children's Fund \& World Health Organization (2015). Progress on sanitation and drinking water: 2015 update and MDG assessment. Geneva: World Health Organization.

United Nations Development Programme (2016b). Human development report 2016: Human development for everyone. New York: United Nations Development Programme.

United Nations Development Programme (2016a). 'Human Development Data'. http://hdr.undp.org/en/data (accessed October 19, 2016).

United Nations General Assembly (2015). Information and communications technologies for development: Report of the Second Committee, Seventieth Session, 15 December 2015. New York: United Nations.
United Nations Statistics Division (2017). 'SDG Indicators Metadata repository'. https://unstats.un.org/sdgs/metadata/ (accessed July 28, 2017).

United Nations (2017). https://sustainabledevelopment.un.org (accessed November 29, 2017).

World Bank (2016a). 'World Bank Country and Lending Groups'. https://datahelpdesk.worldbank.org/knowledgebase/articles/906519 (accessed October 21, 2016).

World Bank (2016b). 'World Development Indicators'. http://data.worldbank org/data-catalog/world-development-indicators (accessed October 15, 2016). 